OPEN ACCESS

Edited by:

Ján A. Miernyk,

Agricultural Research Service (USDA),

United States

Reviewed by:

Robin K. Cameron,

McMaster University, Canada

Kent D. Chapman

University of North Texas,

United States

*Correspondence:

Mee-Len Chye

mlchye@hku.hk

Specialty section: This article was submitted to

Plant Physiology,

a section of the journal

Frontiers in Plant Science

Received: 09 September 2017

Accepted: 03 January 2018

Published: 25 January 2018

Citation:

Hu T-H, Lung S-C, Ye Z-W and

Chye M-L (2018) Depletion

of Arabidopsis ACYL-COA-BINDING PROTEIN3 Affects Fatty Acid

Composition in the Phloem.

Front. Plant Sci. 9:2.

do: $10.3389 / \mathrm{fp} / \mathrm{s} .2018 .00002$

\section{Depletion of Arabidopsis} ACYL-COA-BINDING PROTEIN3 Affects Fatty Acid Composition in the Phloem

\author{
Tai-Hua Hu, Shiu-Cheung Lung, Zi-Wei Ye and Mee-Len Chye* \\ School of Biological Sciences, The University of Hong Kong, Pokfulam, Hong Kong
}

Oxylipins are crucial components in plant wound responses that are mobilised via the plant vasculature. Previous studies have shown that the overexpression of an Arabidopsis acyl-CoA-binding protein, AtACBP3, led to an accumulation of oxylipin-containing galactolipids, and AtACBP3pro::BETA-GLUCURONIDASE (GUS) was expressed in the phloem of transgenic Arabidopsis. To investigate the role of AtACBP3 in the phloem, reverse transcription-polymerase chain reaction and western blot analysis of phloem exudates from the acbp3 mutant and wild type revealed that the AtACBP3 protein, but not its mRNA, was detected in the phloem sap. Furthermore, micrografting demonstrated that AtACBP3 expressed from the $35 \mathrm{~S}$ promoter was translocated from shoot to root. Subsequently, AtACBP3 was localised to the companion cells, sieve elements and the apoplastic space of phloem tissue by immunogold electron microscopy using anti-AtACBP3 antibodies. AtACBP3pro::GUS was induced locally in Arabidopsis leaves upon wounding, and the expression of woundresponsive jasmonic acid marker genes (JASMONATE ZIM-DOMAIN10, VEGETATIVE STORAGE PROTEIN2, and LIPOXYGENASE2) increased more significantly in both locally wounded and systemic leaves of the wild type in comparison to acbp3 and AtACBP3-RNAi. Oxylipin-related fatty acid (FA) (C18:2-FA, C18:3-FA and methyl jasmonate) content was observed to be lower in acbp3 and AtACBP3-RNAi than wildtype phloem exudates using gas chromatography-mass spectrometry. Experiments using recombinant AtACBP3 in isothermal titration calorimetry analysis showed that medium- and long-chain acyl-CoA esters bind (His) $)_{6}$-AtACBP3 with $K_{D}$ values in the micromolar range. Taken together, these results suggest that AtACBP3 is likely to be a phloem-mobile protein that affects the FA pool and jasmonate content in the phloem, possibly by its binding to acyl-CoA esters.

Keywords: acyl-CoA esters, fatty acids, linolenic acid, jasmonate, oxylipins, wounding

\section{INTRODUCTION}

To enhance survival, land plants have developed a complex mechanism to cope with wounding. Early evidence showed that mechanical wounding induces defence-related proteinase inhibitors and their transcripts from potato (Solanum tuberosum) and tomato (S. lycopersicum) (Graham et al., 1986; Farmer and Ryan, 1992) and the vasculature plays an important role in signal 
transduction for plant defence (for a review see Shah, 2009). The vasculature consists of the phloem and the xylem. Water and mineral nutrients are channelled to the source tissues of plants through the xylem (for a review see De Boer and Volkov, 2003), while the phloem, consisting of the parenchyma cells, sieve elements (SE) and companion cells (CC) (for a review see Schulz, 1998), delivers sucrose (Riesmeier et al., 1994), phytohormones (e.g., abscisic acid, auxins, cytokinins, and gibberellins) (for a review see Hoad, 1995), ribonucleic acids (Xoconostle-Cazares et al., 1999), proteins (Hayashi et al., 2000; Yoo et al., 2002; Carella et al., 2016) and lipids (Madey et al., 2002; Guelette et al., 2012). Putative lipid-transfer proteins (LTPs), such as Arabidopsis thaliana DEFECTIVE IN INDUCED RESISTANCE1 (AtDIR1), tomato DIR1 and a putative rice acyl-CoA-binding protein (ACBP), have been identified in the phloem and likely participate in lipid trafficking (Maldonado et al., 2002; Suzui et al., 2006; Mitton et al., 2009). Along with a recent proteomic study that revealed yet more LTPs with putative roles in lipid-mediated signalling in the phloem (Barbaglia et al., 2016), the vasculature, particularly the phloem, shows great potentials for plant scientists to study the mechanisms of lipid transport in plant defence.

Fatty acids (FAs) are an important source of energy reserve in all organisms and constitute the primary composition of lipids (for a review see Ohlrogge and Browse, 1995). In plants, FAs are also essential for the biosynthesis of jasmonic acid (JA) and its derivatives (together referred to jasmonate hereafter) which play many roles in defence (Creelman and Mullet, 1997; Vijayan et al., 1998; Sanders et al., 2000; Franke et al., 2005). Arabidopsides are galactolipid derivatives containing an oxygenated jasmonic precursor, 12-oxo-phytodienoic acid (OPDA) (Stelmach et al., 2001; Hisamatsu et al., 2003, 2005; Andersson et al., 2006; Buseman et al., 2006; Kourtchenko et al., 2007), and many of them have been directly associated with the plant wound responses (Buseman et al., 2006; Kourtchenko et al., 2007). Upon wounding, JA production has been reported to increase in locally wounded and systemic leaves suggesting transport of a systemic wound signal (Glauser et al., 2008, 2009; Mousavi et al., 2013). Glauser et al. (2009) also demonstrated that direct vascular connexions to wounded leaves are crucial to JA augmentation in systemic tissues.

In plants, FAs are activated by acyl-CoA synthetase and converted into acyl-CoA esters (Gerbling et al., 1994). ACBPs have been suggested to maintain the acyl-CoA pools in plants (Yurchenko et al., 2009). In Arabidopsis, six AtACBPs have been postulated to play different roles in phospholipid metabolism and membrane biogenesis as well as homeostasis (for reviews see Xiao and Chye, 2009, 2011a; Du et al., 2016; Ye and Chye, 2016). In Arabidopsis rosettes, the promoter activities of AtACBP1, AtACBP3, and AtACBP6 are detectable in the phloem besides other tissues (Zheng et al., 2012; Xue et al., 2014; Ye et al., 2016a). AtACBP6 is involved in systemic acquired resistance (SAR) (Xia et al., 2012) and it accumulates in the phloem sap collected from SAR-induced leaves (Carella et al., 2016). Only AtACBP1 and AtACBP6 are known to be induced upon abiotic stress treatments (Chen et al., 2008; Xiao et al., 2008; Du et al., 2010, 2013; Liao et al., 2014). AtACBP1 and AtACBP6 also play overlapping roles with other AtACBPs in plant reproduction (Hsiao et al.,
2015; Lung et al., 2017). Recently, AtACBP6 was found to be wound-inducible and to affect jasmonate composition in the phloem (Ye et al., 2016a). So far, only the overexpression of AtACBP3 conferred protection against Pseudomonas syringae DC3000 in transgenic Arabidopsis besides inducing premature leaf senescence (Xiao et al., 2010; Xiao and Chye, 2011b). These phenotypes are likely caused by a shift in lipid homeostasis in the AtACBP3-overexpressors (AtACBP3-OEs) because they accumulated higher amounts of C18:3-CoA esters, phosphatidylethanolamine, lysophospholipids and arabidopsides with a significant decrease in phosphatidylcholine (PC) (Xiao et al., 2010). As the phloem exudate of Arabidopsis has been reported to contain various lipids, such as phospholipids and free FAs (Madey et al., 2002; Guelette et al., 2012), and AtACBP3pro::GUS had been detected in the phloem (Zheng et al., 2012), an investigation was initiated to explore the biological function of AtACBP3 in phloem lipid homeostasis and the plant wound responses. Our results suggest that AtACBP3 is a phloem-mobile and wound-inducible protein that plays a role in balancing the composition of polyunsaturated C18-unsaturated FAs and jasmonate in the phloem.

\section{MATERIALS AND METHODS}

\section{Plant Materials and Growth Conditions}

The Arabidopsis acbp3 mutant (stock no. SALK_012290, ecotype Col-0) contains a single T-DNA insertion on Southern blot analysis (Chan, 2004), and it expressed non-translatable truncated AtACBP3 mRNAs as verified by northern blot analysis and western blot analysis (Xiao et al., 2010). Arabidopsis seeds of the acbp3 mutant, AtACBP3-RNAi lines (ecotype Col-0; Xiao et al., 2010), AtACBP3-OE and wild-type Col-0 were surface-sterilised in diluted bleach (Clorox) solution [final concentration $1.25 \%(\mathrm{w} / \mathrm{v})$ sodium hypochlorite] and $1 \%(\mathrm{v} / \mathrm{v})$ Triton X-100 for $30 \mathrm{~min}$, followed by several washes in sterile water. They were subsequently germinated on Murashige and Skoog (MS) medium. They were stratified for 2 days at $4^{\circ} \mathrm{C}$ in darkness before germination at $21^{\circ} \mathrm{C}$. Plates were incubated in a tissue culture room and seedlings were subsequently potted in soil and grown at $23^{\circ} \mathrm{C} / 21^{\circ} \mathrm{C}$ (day/night) cycles with a day length regime of 16-h light and 8-h dark.

\section{Collection of Phloem Exudate}

Phloem exudates were collected 2-3 h after the onset of light as previously described (Guelette et al., 2012). Fifteen Arabidopsis rosette leaves with petioles from 5- to 6-week-old plants were excised and the cuttings were immediately immersed in ethylenediaminetetraacetic acid (EDTA) solution $(20 \mathrm{mM}$ $\mathrm{K}_{2}$-EDTA, pH 7.0). Subsequently, the petioles were recut to the same length and quickly immersed into $1.3 \mathrm{~mL}$ of the EDTA solution. Leaves were then kept in an opaque and humid container. After $1 \mathrm{~h}$, petioles were rinsed in sterile water to remove residual EDTA and returned to the sterile water. Exudates were collected for 6-8 h under a dark humid condition. Phloem RNA was prepared by adding $100 \mathrm{U}$ of RNase inhibitor (Roche) per $1 \mathrm{~mL}$ of deionized water before collection of phloem exudates. 
The phloem exudates were flash-frozen in liquid nitrogen, lyophilised and stored at $-80^{\circ} \mathrm{C}$ until use.

\section{Reverse Transcription Polymerase Chain Reactions (RT-PCR) Using Phloem mRNA}

Phloem mRNA was extracted using the RNeasy Mini Kit (Qiagen) to detect AtACBP3 (At4g24230) expression in the RT-PCR analysis. According to Guelette et al. (2012), the mRNA of UBC9 (At4g27960) was selected as the positive internal control, because it is known to be present in phloem exudates. The negative internal controls were $r b c L$ (AtCg00490) and $r b c S$ (At5g38410), corresponding to the transcripts of the Rubisco large and small subunits, respectively. The two transcripts ( $r b c L$ and $r b c S$ ) were chosen as negative controls in the RT-PCR analysis of phloem exudates, as two independent studies (Deeken et al., 2008; Guelette et al., 2012) have confirmed their absence in phloem exudates. Total leaf mRNA similarly extracted from the 4 -week-old wild type was used as a positive external control in RT-PCR. Following DNase treatment (Promega), mRNA (200 ng) was reverse-transcribed using the Omniscript RT Kit (Qiagen). The cDNA from phloem exudates and leaf mRNA samples was used as templates in PCR mixes with Taq DNA polymerase (Promega) for amplification under 40 cycles of $94^{\circ} \mathrm{C}, 30 \mathrm{~s}$; $53^{\circ} \mathrm{C}, 30 \mathrm{~s}$, and $72^{\circ} \mathrm{C}, 30 \mathrm{~s}$ using primers of $U B C 9, r b c L, r b c S$, and AtACBP3 (Supplementary Table S1). Equal volumes of PCR products were loaded onto a $2 \%$ agarose gel for electrophoresis.

\section{Micrografting of Arabidopsis}

Micrografting experiments were carried out according to Turnbull et al. (2002) with modifications. Seeds of Col-0, AtACBP3-OEs and the acbp3 mutant were surface-sterilised and sown onto MS plates. MS plates were orientated vertically at $4^{\circ} \mathrm{C}$ for 4 days for seed stratification, and subsequent germination was carried out at $23^{\circ} \mathrm{C} / 21^{\circ} \mathrm{C}$ (day/night) cycles with a regime of 16-h light and 8-h dark. The micrografting experiment was performed using 7-day-old seedlings. Upper hypocotyls of seedlings containing shoot apical meristem and cotyledons were excised from whole seedlings with a surgical blade and re-aligned with lower hypocotyls, which were separated in the same manner. All grafted plants were examined before planting on soil. Grafted plants that had adventitious roots at the grafting junctions were discarded. Grafted plants with no adventitious roots were grown vertically for 7 days in Petri dishes in a humid environment. Successful reunions were transferred onto soil and grown as normal plants. Phloem exudates from 6-week-old scion (rosette leaf) or rootstock tissues were harvested for protein extraction after micrografting.

\section{Western Blot Analysis}

Phloem exudates collected from the 5-week-old wild type and the acbp 3 mutant were directly used for western blot analysis. Sterile water was added into the lyophilised exudates. Protein concentration was determined according to Bradford (1976) and $30 \mu \mathrm{g}$ of protein were loaded for sodium dodecyl sulphate polyacrylamide gel electrophoresis (SDS-PAGE), followed by protein transfer to polyvinylidene fluoride membranes (GE
Healthcare) using the Trans-Blot Cell (Bio-Rad) at $25 \mathrm{~V}$ for $20 \mathrm{~min}$. The rabbit polyclonal anti-AtACBP3 antibodies were raised against a synthetic peptide corresponding to amino acids 59 to 72 of AtACBP3 (DARVLESQRNFQVV) (Xiao et al., 2010). The antibodies were preabsorbed overnight in acbp3 mutant protein extract to remove unspecific binding prior to use (Supplementary Figure S1). The blots were incubated with the preabsorbed antibodies. Detection of immuno-reactive signals was performed using the Amersham ECL Prime Western Blotting Detection Reagent according to the manufacturer's instruction.

\section{Immunoelectron Microscopy (IEM)}

Five-week-old stems were fixed in a solution of $2 \%$ paraformaldehyde and $1.25 \%$ glutaraldehyde in $50 \mathrm{mM}$ piperazine- $N, N$-bis (2-ethanesulfonic acid) $(\mathrm{pH}$ 7.2) for $1 \mathrm{~h}$ under vacuum and then further incubated at $4^{\circ} \mathrm{C}$ overnight with gentle shaking. The tissues were dehydrated in a graded ethanol series, infiltrated in stepwise increments of London Resin White (London Resin Company) and polymerised at $65^{\circ} \mathrm{C}$ for over $24 \mathrm{~h}$ (His et al., 2001).

Immuno-gold labelling was carried out according to Ye et al. (2016b) with modifications. Ultra-thin sections $(80 \mathrm{~nm})$ were prepared and mounted on nickel grids. Grids were blocked on the liquid surface of $30 \mu \mathrm{L}$ blocking solution droplets containing $1 \%$ bovine serum albumin (BSA) and 1\% TTBS (20 mM Tris, $500 \mathrm{mM} \mathrm{NaCl}, 0.1 \%$ Tween-20, pH7.5) for $1 \mathrm{~h}$ at room temperature and subsequently incubated in anti-AtACBP3 antibodies diluted $1: 50(\mathrm{v} / \mathrm{v})$ at $4^{\circ} \mathrm{C}$ overnight. In the negative controls, the primary antibodies were replaced with blocking solution or preimmune serum diluted 1:50 (v/v). After three 15-min washes with blocking buffer, the grids were incubated with a 1:100 dilution of anti-rabbit antibodies conjugated to $10 \mathrm{~nm}$ gold (Sigma-Aldrich) at room temperature for $1 \mathrm{~h}$. Grids were washed twice in TTBS-BSA, once in TTBS and sterile water, and each rinse lasted $15 \mathrm{~min}$. The grids were subsequently stained with $2 \%$ uranyl acetate for $1 \mathrm{~min}$ at room temperature and photographed under a Philips 100CM TEM immunoelectron microscope at $80 \mathrm{kV}$.

Images in Figure 2 and other images collected from the same experiment were analysed for gold labelling densities in different cell types according to Lee et al. (2011) with modifications. All raw images in this analysis are available in Supplementary IEM Images. Total number of gold particles and total area from each cell type [CC $(n=7)$, SE $(n=7)$ and extracellular space (ES) $(n=7)]$ were counted and measured in Adobe Photoshop CC 2015. The density of gold particles from each cell type is equal to the total number of gold particles divided by its total area $\left(\mu \mathrm{m}^{2}\right)$.

\section{Wound Treatment of Plants}

Two days prior to any treatment, plants were transferred to 24-h constant light condition to eliminate the induction of AtACBP3 by darkness (Xiao et al., 2010; Zheng et al., 2012). Wound treatment was carried out according to Farmer et al. (2013) and Mousavi et al. (2013). Five-week-old plants were wounded by gently crushing leaf 8 of the plants with a pair of forceps (Farmer et al., 2013). Tissues of locally wounded [leaf 8; Mousavi et al. (2013)] and systemic [leaf 13; Mousavi et al. (2013)] leaves were 
collected $1 \mathrm{~h}$ post wounding (hpw), 2 and $4 \mathrm{hpw}$ for relative gene expression analysis. For quantitative GUS assays, all leaves were wounded and total proteins were extracted. For quantitative realtime polymerase chain reactions (qRT-PCR), unwounded plants (Col-0, acbp3, and AtACBP3-RNAi) were used as baseline control to monitor the gene expression levels, while gene expression in wounded $a c b p 3$ and AtACBP3-RNAi plants were compared with those in wounded Col- 0 treated under the same conditions.

\section{Quantitative and Histochemical GUS Assays}

Quantification of GUS activity was carried out by measuring the cleavage of the substrate (Jefferson et al., 1987). The substrate, 4-methylumbelliferyl- $\beta$-D-glucuronide (MUG) was purchased from Sigma-Aldrich. Tissues were collected into Eppendorf tubes and frozen in liquid nitrogen, followed by homogenisation. Subsequently, $1 \mathrm{~mL}$ GUS Extraction Buffer (150 mM sodium phosphate $\mathrm{pH}$ 7.0, $10 \mathrm{mM}$ EDTA, $10 \mathrm{mM} \beta$-mercaptoethanol, $0.1 \%$ Triton $\mathrm{X}-100,0.1 \%$ sarcosyl) was added, and samples were gently agitated. The homogenised mixture was centrifuged at $13000 \mathrm{rpm}$ for $15 \mathrm{~min}$. Two hundred $\mu \mathrm{L}$ of supernatant from each sample was used for MUG assays and protein quantification. A $10-\mu \mathrm{L}$ sample extract and $130-\mu \mathrm{L}$ Assay Buffer (GUS Extraction Buffer containing 1.2 mM MUG) were mixed and the reaction incubated in the dark at $37^{\circ} \mathrm{C}$ for $20 \mathrm{~min}$. Subsequently, $10 \mu \mathrm{L}$ of the reaction was added to $190 \mu \mathrm{L}$ Stop Buffer (200 mM sodium carbonate) in a 96-well plate. Fluorescence excited at $355 \mathrm{~nm}$ was quantified on a plate reader (BMG LABTECH) at $460 \mathrm{~nm}$. A standard curve corresponding to $0,0.25,0.5,2.5,5,25$, and $50 \mu \mathrm{M}$ 4-methylumbelliferone (MU) was included for calculation of liberated MU. The fluorescence assay measurements were normalised for protein concentration and recorded as nmoles $\mathrm{MU} \mathrm{min}^{-1} \mathrm{mg}^{-1}$ protein.

For histochemical GUS assay (Jefferson et al., 1987), Arabidopsis leaves was submerged in X-Gluc solution [1 mg $\mathrm{mL}^{-1} X$-Gluc, $100 \mathrm{mM}$ sodium phosphate, $\mathrm{pH} 7.5,2 \mathrm{mM}$ $\mathrm{K}_{3} \mathrm{Fe}(\mathrm{CN})_{6}, 2 \mathrm{mM} \mathrm{K} \mathrm{K}_{4} \mathrm{Fe}(\mathrm{CN})_{6}, \quad 0.1 \%$ Triton $\left.\mathrm{X}-100\right]$ and infiltrated by vacuuming for $1 \mathrm{~h}$, followed by a 4 -h incubation at $37^{\circ} \mathrm{C}$ in darkness. Chlorophyll removal was performed by using $70 \%$ ethanol. Samples were then placed above a light-box for photography.

Two sets of controls were used in both GUS assays; a vector line (pBI101) was used as a negative control, and unwounded AtACBP3pro::GUS transgenic plants served as a baseline control in GUS expression.

\section{Quantitative Real-Time Polymerase Chain Reactions (qRT-PCR)}

Total leaf mRNA was extracted from 5-week-old Arabidopsis using the RNeasy Mini Kit (Qiagen) followed by DNase (Promega) treatment. First-strand cDNA was synthesised using the Superscript First-Strand Synthesis System (Invitrogen). Subsequently, qRT-PCR were carried out using the FastStart Universal SYBR Green Master Mix (Roche) on a StepOne Plus Real-Time PCR System (Applied Biosystems). Primers

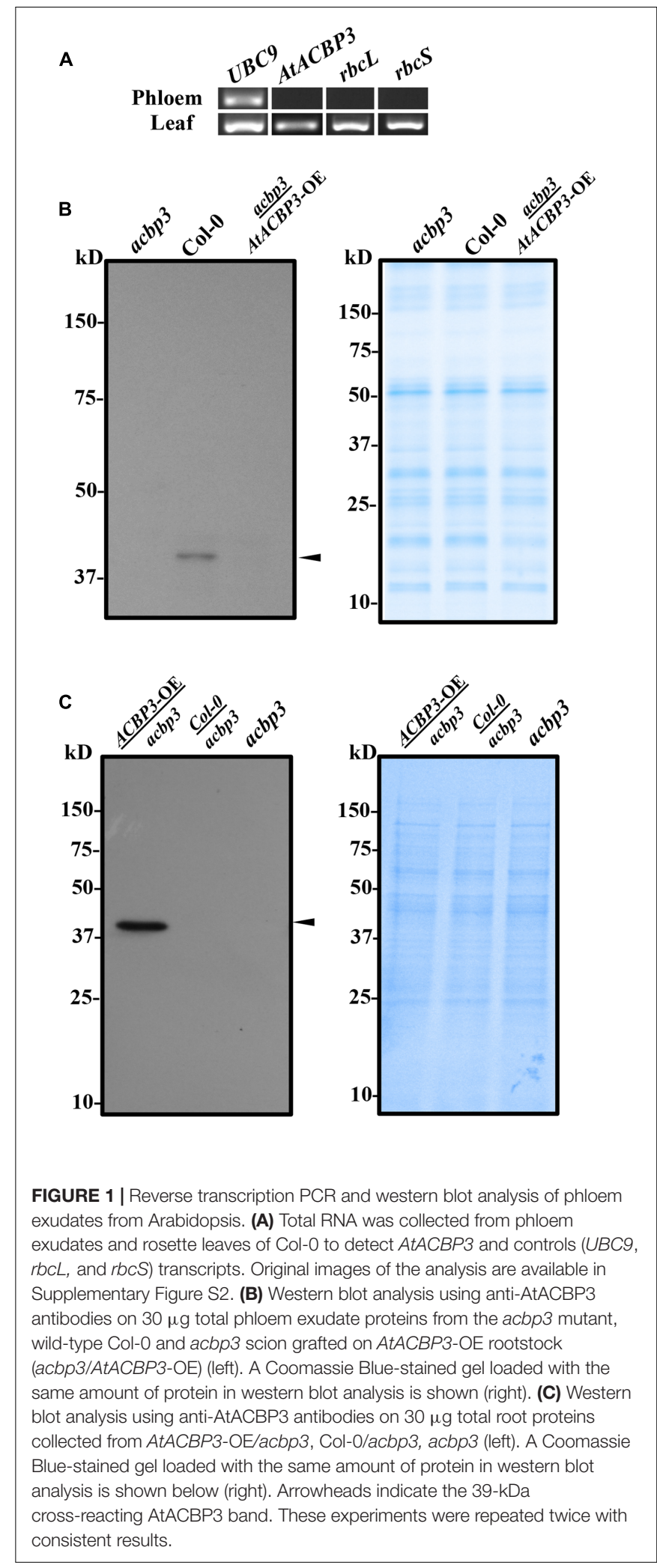

of JASMONATE ZIM-DOMAIN10 (JAZ10), LIPOXYGENASE2 (LOX2), VEGETATIVE STORAGE PROTEIN2 (VSP2), AtACBP3 and ACTIN2 are shown in Supplementary Table S1. Relative gene 

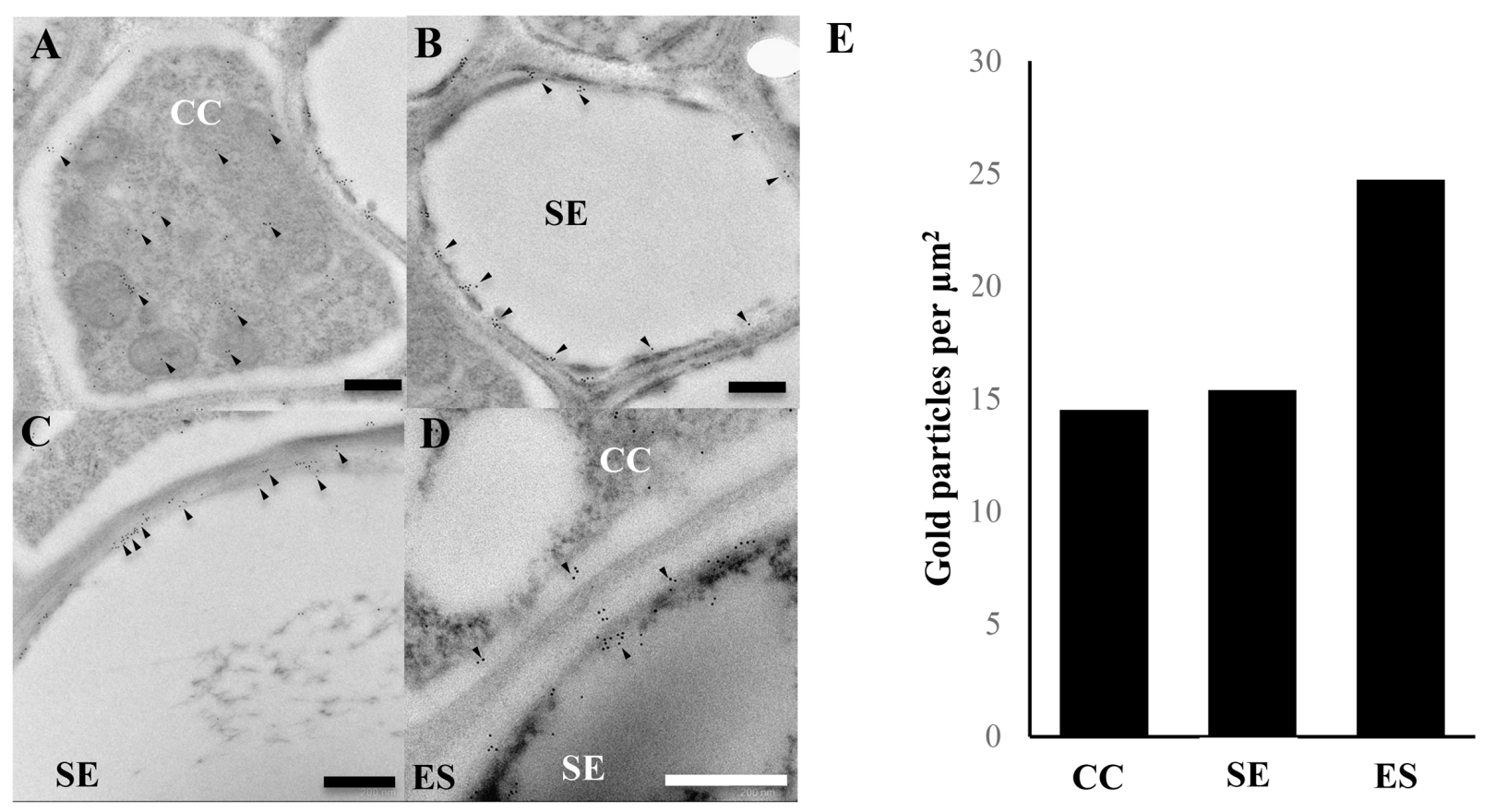

FIGURE 2 | Immunogold localisation of AtACBP3 using anti-AtACBP3 antibodies in transmission electron microscopy of cross sections of apical stems from 5-week-old Arabidopsis. (A) Companion cell. (B) Sieve element. (C,D) Extracellular space. (E) Densities of gold particles were quantified per $\mu m^{2}$. Arrowheads indicate gold particles. Multiple floral stems from different individual plants sectioned and analysed in this experiment showed consistent results. Further images are available in Supplementary IEM Images. CC, companion cell; ES, extracellular space; SE, sieve element. Scale bar $=0.5 \mu \mathrm{m}$.

expression of JAZ10 (1 hpw), LOX2 (2 hpw), VSP2 (4 hpw), and AtACBP3 (1 hpw) was normalised to the expression of ACTIN2. The duration of wound treatment for analysis of each marker gene (JAZ10,LOX2, and VSP2) was according to Glauser et al. (2009) and Mousavi et al. (2013). Three independent biological repeats were performed to analyse the relative mRNA expression.

\section{FA Analysis by Gas Chromatography- Mass Spectrometry (GC-MS)}

FA analysis was conducted following Carvalho and Malcata (2005) with modifications. Phloem exudates collected and pooled from 150 leaves were dissolved in a transmethylation solution containing $1 \mathrm{~mL}$ of toluene, $2 \mathrm{~mL}$ of $1 \%(\mathrm{v} / \mathrm{v})$ sulphuric acid in methanol together with $5 \mu \mathrm{L}$ of an internal standard [C19:0 (1 $\mathrm{mg} \mathrm{mL}^{-1}$ hexane)]. The transmethylation solution containing phloem exudates was incubated for $12 \mathrm{~h}$ at $50^{\circ} \mathrm{C}$ for the transmethylation of FAs. After several washes with $5 \%$ (w/v) $\mathrm{NaCl}$ and hexane, the hexane layer was washed with $4 \mathrm{~mL} 2 \%(\mathrm{w} / \mathrm{v})$ $\mathrm{KHCO}_{3}$ and then transferred into another test tube followed by vigorous vortexing. Nitrogen gas was passed through each tube to evaporate the hexane. Then $100 \mu \mathrm{L}$ of hexane was re-added to the test tube to concentrate the FA residues. One $\mu \mathrm{L}$ of the hexane supernatant, containing the FAs, was analysed by Agilent $6890 \mathrm{~N}$ equipped with a 5973 Mass Selective Detector (MSD) and a $30 \mathrm{~m} \times 0.250 \mathrm{~mm}$ DB-WAX column $(0.25 \mu \mathrm{m}$ in film thickness). The samples were positioned and then automatically injected into the column. For sample detection, the oven temperature was increased from 100 to $230^{\circ} \mathrm{C}$ with a rate of $4^{\circ} \mathrm{C} \mathrm{min}-1$ and postrun at $235^{\circ} \mathrm{C}$ for $4 \mathrm{~min}$. The GC/MSD On-line Data Analysis was used for data processing after data acquisition; the FAME library was used for compound identification. Quantification of FA species was calculated by comparing the peak area of each FA to the internal standard, followed by normalisation to ng/leaf.

\section{Isothermal Titration Calorimetry Assays (ITC)}

(His) 6 -AtACBP3 expressed from plasmid pAT223 in Escherichia coli BL21(DE3) pLysS cells was purified as previously described (Leung et al., 2006). ITC assays were performed using a MicroCal iTC200 system (GE Healthcare). Acyl-CoA esters (C12:0-, C14:0-, C16:1-, C17:0-, C18:2-, and C18:3-CoA esters) were purchased from Avanti Polar Lipids. The $600 \mu \mathrm{M}$ acyl-CoA ester in the titration syringe was 20 -fold higher than the protein concentration $(30 \mu \mathrm{M})$ in the reaction chamber. Solutions of acyl-CoA esters and (His) 6 -AtACBP3 were degassed under vacuum. Assays were conducted at $25^{\circ} \mathrm{C}$, and injections were initiated after equilibration to baseline stability. The acyl-CoA ester $(1.5 \mu \mathrm{L})$ was injected 20 times into the reaction chamber and each injection lasted $3.6 \mathrm{~s}$ at an interval of $120 \mathrm{~s}$ between injections. Immediate mixing was ensured by stirring. Raw data was integrated, corrected for non-specific heat, and analysed using the ORIGIN software (OriginLab). Dissociation constants $\left(K_{D}\right)$ were calculated by non-linear regression fitting the isotherm. Each binding assay was performed at least twice independently. 


\section{RESULTS}

\section{AtACBP3, But Not Its mRNA, Was Detected in Wild-Type Col-0 Phloem Exudates}

Given that AtACBP3pro::GUS was localised in the phloem (Zheng et al., 2012), phloem exudates were collected from leaf petioles to verify whether AtACBP3 and/or its mRNA were present in the phloem sap. In RT-PCR analysis, the positive control (UBC9) was detected both in the phloem exudates and leaves, indicating that mRNA extraction and RT-PCR analysis were properly performed. Two negative controls ( $r b c L$ and $r b c S$ ) were only detectable in leaves but not in phloem exudates (Figure 1A), confirming the collection of phloem exudates were free from cellular contaminations of other cell types. Using an AtACBP3-specific primer pair (ML1202 and ML1203) (Supplementary Table S1), the 174-bp AtACBP3 mRNA was not detected in phloem exudate (Figure 1A), but western blot analysis showed a strong 39-kDa AtACBP3 cross-reacting band in wild-type phloem exudate (Figure 1B). Through micrografting, a 39-kDa AtACBP3 cross-reacting band was also detected in root protein extracts of acbp3 rootstock micrografted below AtACBP3-OE scions while the same cross-reacting band was not detectable in non-grafted acbp3 roots, indicating that AtACBP3 is mobile from shoot to root (Figure 1C). However, no such band was detected in the phloem exudates collected from acbp3 scions micrografted above the AtACBP3-OE rootstocks, implying that AtACBP3 is not mobile from root to shoot (Figure 1B).

\section{AtACBP3 Was Immunolocalised to Companion Cells, Sieve Elements and the Extracellular Space of the Phloem}

To further investigate the localisation of AtACBP3 in the phloem, IEM was carried out after preabsorption of antibodies (Supplementary Figure S1). Immunogold particles were localised in the phloem (Figure 2), particularly in the cytosol of CC (Figure 2A) and SE (Figure 2B). Immunogold particles were also detected in ES (Figures 2C,D), but not in the control incubated with blocking solution (Supplementary Figure S3). A quantitative analysis of gold particle densities showed that the labelling was localised more preferably to ES in comparison to CC and SE (Figure 2E).

\section{AtACBP3 Expression Was Induced by Mechanical Wounding}

To investigate the effect of wounding on the expression of AtACBP3, AtACBP3pro::GUS plants were utilised in quantitative and histochemical GUS assays. The results of GUS activity using 4-week-old transgenic plants, 1-4 hpw, showed that AtACBP3pro::GUS expression peaked at $3 \mathrm{hpw}$ in comparison to unwounded AtACBP3pro::GUS (Figure 3A). Histochemical staining of AtACBP3pro::GUS also confirmed that AtACBP3 expression was induced by wounding with the highest expression at $3 \mathrm{hpw}$, while the wounded vector line showed no expression (Figure 3B).

\section{The acbp3 Mutant Was Less Responsive to Wound in Local and Distal Leaves}

The role of $A t A C B P 3$ in the wound response was investigated by comparing wild type, acbp3 and AtACBP3-RNAi leaves in qRTPCR assays examining JAZ10, LOX2 and VSP2 expression, as they are deemed to be robust wound-responsive JA marker genes (Bell et al., 1995; Liu et al., 2005; Yan et al., 2007). The expression of JAZ10, LOX2, VSP2 was drastically elevated 1, 2, and 4 hpw in the wild type (Figures 4A-C), while their expression was significantly reduced in acbp3 and AtACBP3-RNAi (Figures 4A-C and Supplementary Figure S4). Furthermore, the expression of the marker genes was higher in wild-type than either acbp3 or AtACBP3-RNAi distal leaves, indicating that the wound response was adversely affected in acbp3 and AtACBP3-RNAi lines. Another line of evidence on the wound-inducibility of $A t A C B P 3$ was reflected in the upregulation of its mRNA (approximately five times higher at $1 \mathrm{hpw}$ in locally wounded leaves), in comparison to little expression in the distal leaves (Figure 4D).

The differences in expression of the three marker genes before and after wounding were also investigated in an acbp3 complemented line [acbp3-C1; generated using a 35S::AtACBP3 construct as verified by Xiao et al. (2010)]. However, acbp3-C1 did not show the same extent of induction of the three marker genes in wounded leaves as in the wild type, and the induction of JAZ10 and VSP2 was significantly upregulated only in distal leaves (Supplementary Figure S5). When comparing the innate expression level of JAZ10, LOX2, and VSP2 between acbp3-C1 and wild type, it was noted that the expression of JAZ10 in unwounded acbp3-C1 was 15 times that of the wild type. However, the expression of LOX2 and VSP2 decreased when compared to the wild type (Supplementary Figure S6).

\section{Reduced Levels of Defence-Related FAs Accumulate in acbp3 Mutant and AtACBP3-RNAi Lines}

GC-MS analysis of phloem exudates from the wild-type Col-0, the acbp3 mutant as well as the AtACBP3-RNAi lines revealed that C16:0- and C18:0-FAs were the major FAs in all genotypes (Figure 5). Levels of defence-related C18:2-FA and C18:3-FA decreased in acbp3 and AtACBP3-RNAi in comparison to the wild type (Figure 5). Also, a decrease in methyl jasmonate (MeJA) in both acbp3 and AtACBP3-RNAi and an accumulation of saturated C12- and C14-FAs in acbp3 were observed in comparison to the wild type (Figure 5).

\section{Recombinant (His) 6 -AtACBP3 Binds Defence-Related Acyl-CoA Esters In Vitro}

ITC assays were next performed to expand on the in vitro binding profile of AtACBP3 with acyl-CoA esters. A range of 


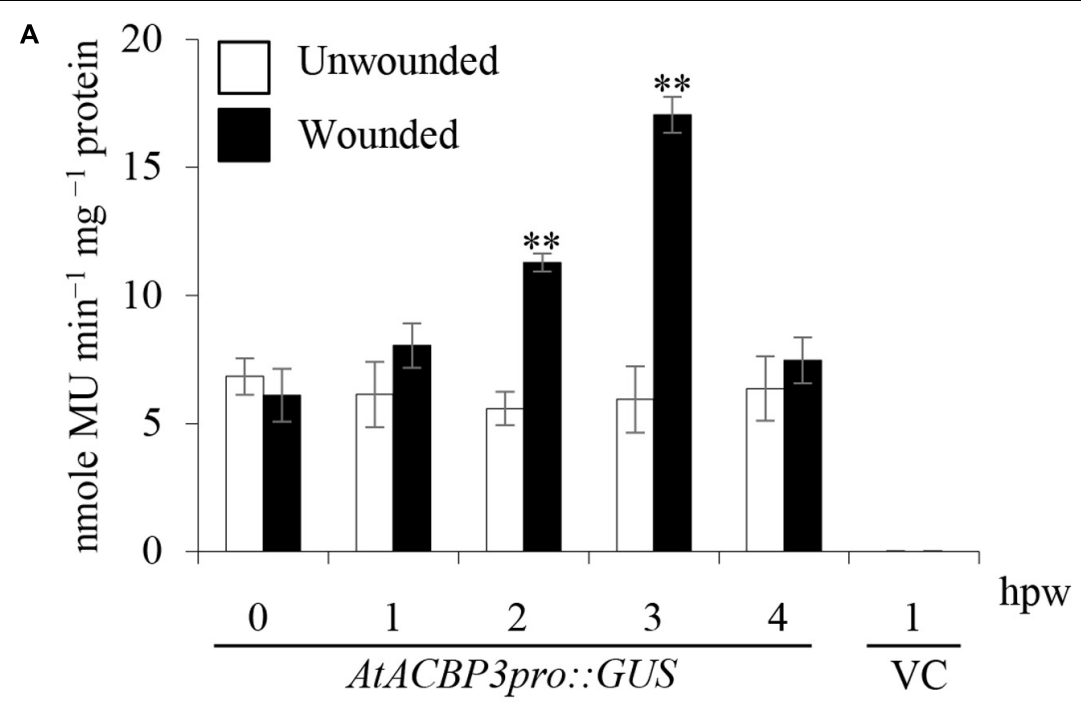

B
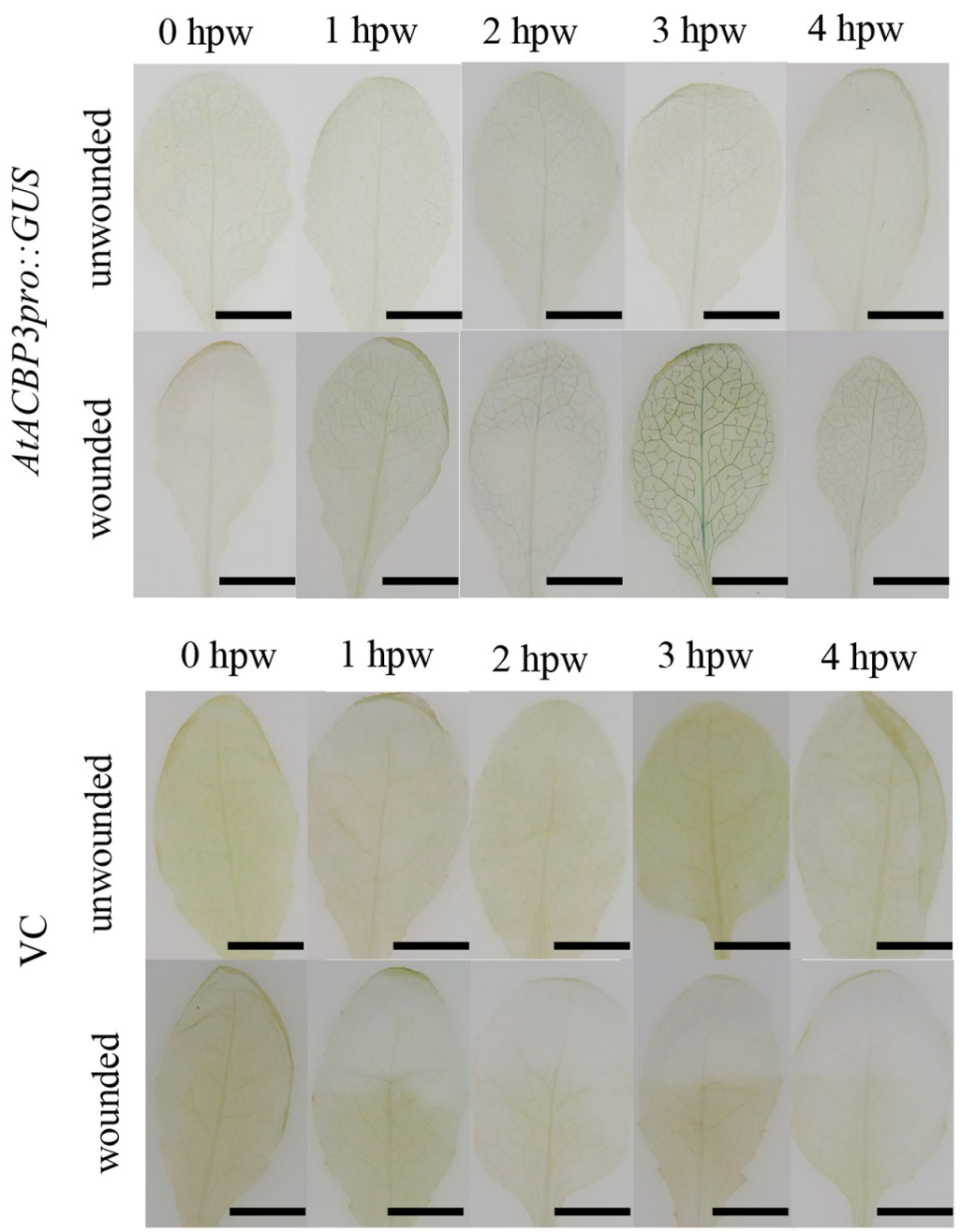

FIGURE 3 | GUS activity assays of transgenic Arabidopsis AtACBP3pro::GUS plants following wounding. (A) Four-week-old AtACBP3pro::GUS transgenic plants were wounded with a pair of forceps and harvested at 1, 2, 3, and $4 \mathrm{~h}$ post wounding (hpw) for quantitative GUS activity measurements. Vector (pBl101.3)-transformed plants were analysed at $1 \mathrm{hpw}$ and served as a negative control, while unwounded AtACBP3pro::GUS plants were used as a baseline control. 
FIGURE 3 | "**” indicates statistically significant difference ( $P<0.01, n=3$ by Student's $t$-test) in comparison to unwounded samples collected at the same time point. Error bars represent standard deviations. (B) A representation of histochemical staining of wounded 4-week-old leaves from AtACBP3pro::GUS and vector (pBl101.3)-transformed (VC) Arabidopsis. These experiments were repeated twice with consistent results. Scale bars $=0.8 \mathrm{~cm}$.

A

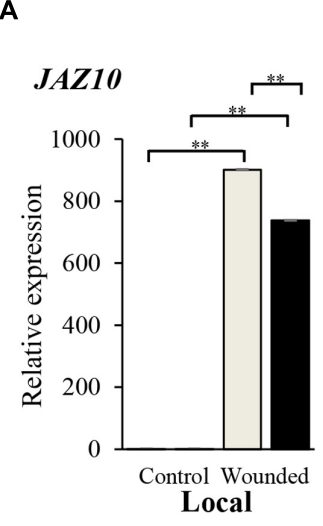

C

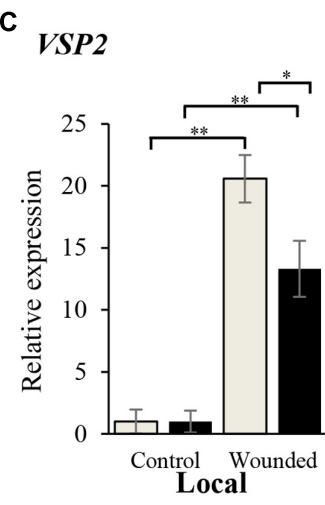

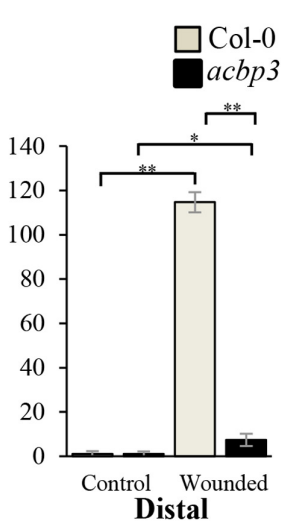
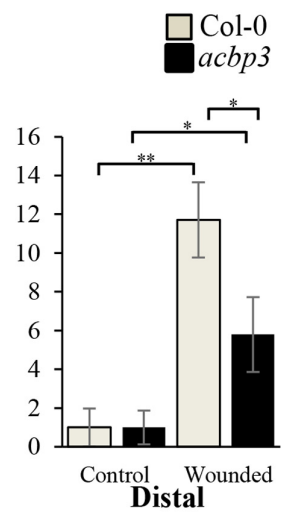

B

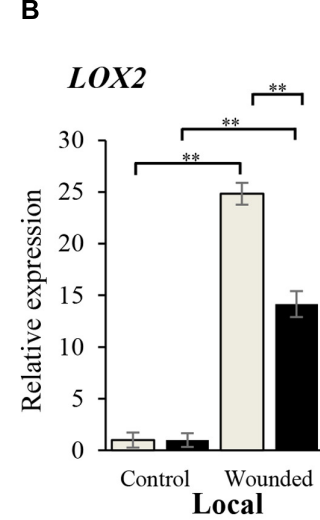

D

AtACBP3

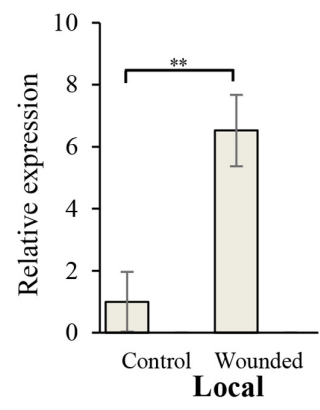

$\square$ Col-0

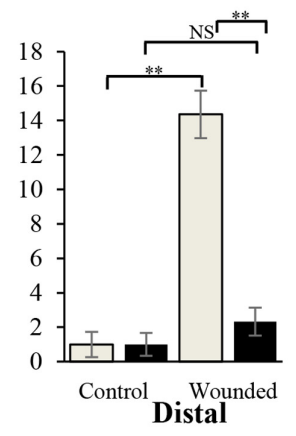

$\square \mathrm{Col}-0$ acbp 3

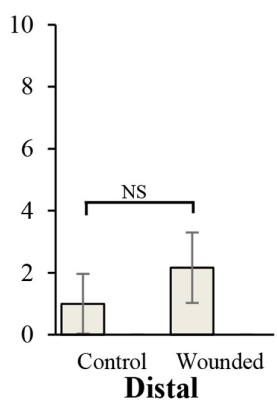

FIGURE 4 | Relative expression of AtACBP3 and marker genes in the Arabidopsis jasmonate pathway after wounding. Rosette leaves harvested from 5-week-old Col-0 and acbp3 were leaf 8 (wounded locally) and leaf 13 (distally wounded at leaf 8). Numbering of rosette leaves was according to Farmer et al. (2013).

(A) Relative expression of JAZ10 $1 \mathrm{~h}$ post wounding (hpw) following Mousavi et al. (2013). (B) Relative expression of LOX2 (2 hpw) following Glauser et al. (2009). (C) Relative expression of VSP2 (4 hpw) following Mousavi et al. (2013). (D) Relative expression of AtACBP3 1 hpw. Error bars represent standard deviation in each analysis. Square brackets indicate which two groups were compared using the Student's $t$-test. ${ }^{* *} P<0.01, n=3$; ${ }^{*} P<0.05, n=3$; NS, not significant, $n=3$;

Local, wounded leaf 8; Distal, leaf 13 distal to wounded leaf 8 . These experiments were repeated twice with consistent results.

medium- and long-chain acyl-CoA esters corresponding to the FAs identified in the phloem exudates were selected for analysis. The binding isotherms of recombinant (His) ${ }_{6}$-AtACBP3 titrated with C12:0-, C14:0-, C18:2-, and C18:3-CoA esters at $25^{\circ} \mathrm{C}$ are displayed in Figures 6, 7. ITC assays were carried out at two different $\mathrm{pH}$ values, $\mathrm{pH} 7.0$ (Figures 6A,C, 7A,C) and $\mathrm{pH}$ 6.4 (Figures 6B,D, 7B,D), because AtACBP3 is expected to be subjected to an acidic $\mathrm{pH}$ when targeted to the apoplast and the phloem (Gao et al., 2004; Leung et al., 2006; Hijaz and Killiny, 2014). All four acyl-CoA esters were shown to bind (His) $6^{-}$ AtACBP3 in vitro, with $K_{D}$ values in the micromolar range (Figures 6, 7). The assays using C12:0- and C18:3-CoA esters also indicated lower $K_{D}$ values at $\mathrm{pH} 6.4$ in comparison to $\mathrm{pH}$ 7.0 (Table 1). However, (His) $)_{6}$-AtACBP3 did not bind MeJA (Supplementary Figure S8), suggesting that AtACBP3 is not likely to transport MeJA directly in the phloem.

\section{DISCUSSION}

\section{AtACBP3 Is Likely an Apoplastic Phloem-Mobile Protein}

As mature SEs are enucleated, it is likely that the AtACBP3 protein which was detected in phloem exudates on western blot analysis (Figure 1), is synthesised in the neighbouring CCs or immature SEs and subsequently exported to mature SEs. Indeed, IEM localised AtACBP3 to both cell types (Figure 2). Detection of AtACBP3 in the apoplast is consistent with previous observation that AtACBP3 is targeted extracellularly (Leung et al., 2006). Together with the detection of AtACBP3 in wild-type phloem exudate (Figure 1B) and the promoter activity of AtACBP3 in the root vasculature of transgenic Arabidopsis seedlings (Supplementary Figure S9) and 32-day-old mature plants (Zheng et al., 2012), the detection of AtACBP3 in the roots of grafted 


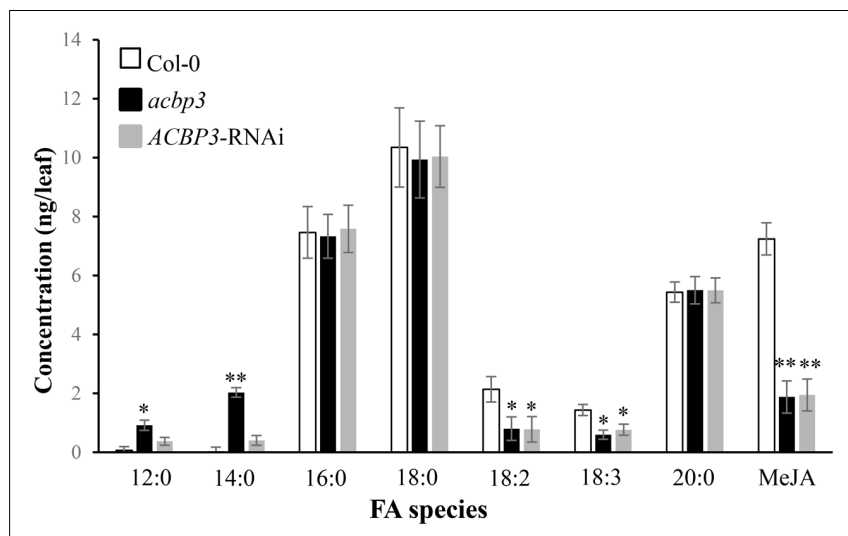

FIGURE 5 | Quantitative gas chromatography-mass spectrometry analysis of fatty acids from phloem exudates of 5-week-old wild-type Col-0 Arabidopsis, acbp3 and AtACBP3-RNAi lines. Error bars represent standard deviation $(n=3)$ in each analysis. The Student's $t$-test was used for statistical analyses. "*" indicates a statistically significant $(P<0.05)$ elevation or reduction in comparison with the wild-type Col-0. "**" indicates a very statistically significant different $(P<0.01)$ elevation or reduction in comparison with the wild-type Col-0. These experiments were repeated twice with consistent results.

plants is not surprising and further suggests that AtACBP3 can be transported from shoot to root (Figure 1C).

Proteins previously identified in the phloem include signalling molecules in flowering time regulation and plant defence (Corbesier et al., 2007; Mathieu et al., 2007; Champigny et al., 2013; Carella et al., 2016) as well as a sucrose $/ \mathrm{H}^{+}$symporter, AtSUC2 (Srivastava et al., 2008). Phloem LTPs have been postulated to participate in systemic transport related to SAR in the phloem (Champigny et al., 2013; Barbaglia et al., 2016). AtDIR1 is an apoplastic phloem LTP that was reported to function in long-distance transport related to SAR in the phloem (Maldonado et al., 2002; Champigny et al., 2013). Its ability to interact with lipids was confirmed by observation of its binding to two lysophosphatidylcholines with $K_{D}$ values in the nanomolar range (Lascombe et al., 2008).

The movement of proteins via plasmodesmata into SEs has been demonstrated by Balachandran et al. (1997) and Ishiwatari et al. (1998). More recently, PLASMODESMATA-LOCALISED PROTEIN5 (PDLP5) was reported to mediate cell-to-cell communication (Lee et al., 2011), and the overexpression of PDLP5 affected the long-distance movement of AtDIR1 (Carella et al., 2015). Although AtDIR1 localises to the apoplast, it may access the phloem via the plasmodesmata, either after cleavage of its signal peptide or from a cytosolic or ER pool, such that AtDIR1 protein accesses the phloem via plasmodesmata during SAR (Champigny et al., 2011). Given the demonstrated association of AtACBP3 with the ER/Golgi complex as well as its apoplastic localisation (Xiao et al., 2010) and involvement in SAR (Xiao and Chye, 2011b; Xia et al., 2012), it is possible that some AtACBP3 protein may be transported symplastically via the plasmodesmata similar to AtDIR1. In fact, another AtACBP, AtACBP6 has been shown to interact with plasmodesmata-localised protein, PDLP8 (Ye et al., 2017) and is localised to the plasmodesmata in the phloem (Ye et al., 2016a). Taken together, these data suggest that an intracellular pool of AtACBP3 may access SEs via the plasmodesmata for long-distance transport in the phloem.

\section{AtACBP3 May Participate in Jasmonate Production after Wounding}

In this study, AtACBP3 was demonstrated to be locally woundinducible at $2 \mathrm{hpw}$ and peaked at $3 \mathrm{hpw}$ as shown in Figure 3. Depletion of AtACBP3, however, impaired the induction of wound-responsive JA marker genes in both local and distal leaves after wounding (Figure 4). However, a similar level of induction in marker gene expression was not detected in the complementary line ( $a c b p 3-\mathrm{C} 1)$ (Supplementary Figures S4, $\mathrm{S} 5)$. This observation in acbp3-C1 may be attributed to the use of the $35 S$ promoter driving $A t A C B P 3$ resulting in an increased amount of endogenous salicylic acid (SA) (Xiao and Chye, 2011b) which may have interfered with JA biosynthesis (discussed in Caarls et al., 2015). Furthermore, C18:3-FA and MeJA accumulation was lower in the phloem exudate of acbp3 and AtACBP3-RNAi excised leaves in comparison to the wild type (Figure 5). The rapid accumulation of jasmonate in distal leaves after wounding has been well characterised (Glauser et al., 2008, 2009). But the mechanism(s) on how these wound signals are mobilised systemically remains to be resolved. In tomato and Arabidopsis, it has been suggested that jasmonate itself is a systemic signal (Li et al., 2002; Thorpe et al., 2007; Sato et al., 2011; Chauvin et al., 2013; Gasperini et al., 2015). On the other hand, a competing theory suggests that JA-related leaf-toleaf wound signalling and the systemic biosynthesis of JA are facilitated by electric signals known as wound-activated surface potential changes (Mousavi et al., 2013).

To this end, there are two possibilities on the role of AtACBP3 in jasmonate biosynthesis in the phloem. In Arabidopsis, PC homeostasis is crucial for plastidic galactolipid biosynthesis (Warwick et al., 1986; Wang et al., 2014). Upon wounding, free C18:3-FA is released from plastid membranes (Narváez-Vásquez et al., 1999; Ishiguro et al., 2001) and its content increases in leaves (Conconi et al., 1996), thereby providing the precursors for JA biosynthesis (for a review see Koo and Howe, 2009). AtACBP3-OEs have been reported to have markedly lower PC but higher galactolipid, including arabidopside, content than the wild type (Xiao et al., 2010), suggesting that AtACBP3 may participate in the transition of extraplastidic lipids from PC to galactolipids. Depletion of AtACBP3 in the phloem in Arabidopsis rosettes supports its involvement in the homeostasis of extraplastidic lipid exchange (Xiao et al., 2010) in the phloem and production of JA upon or after wounding (Figure 5). Another possibility is that AtACBP3 regulates arabidopsides in the phloem as they have been widely postulated to function in wounding and JA production (Stelmach et al., 2001; Hisamatsu et al., 2003, 2005; Andersson et al., 2006; Buseman et al., 2006; Kourtchenko et al., 2007). Wounding and insect infestations can trigger the accumulation of arabidopsides and other 9LOX-derived oxylipins in Arabidopsis (Buseman et al., 2006; Nalam et al., 2012), and AtACBP3-OEs have been shown to overaccumulate arabidopsides (Xiao et al., 2010). 
A

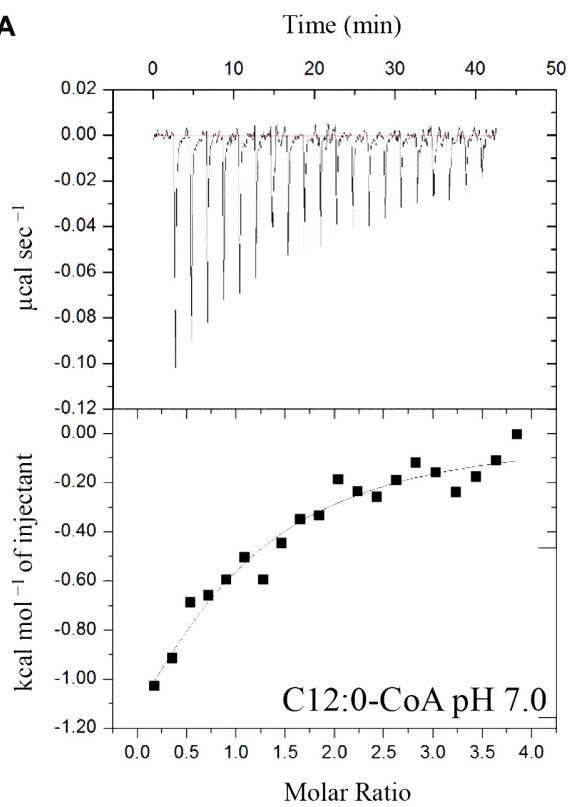

C

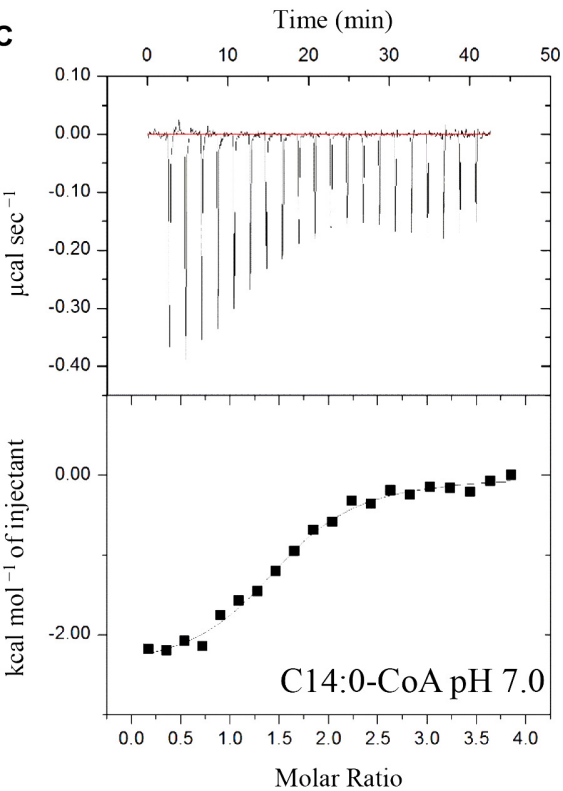

B

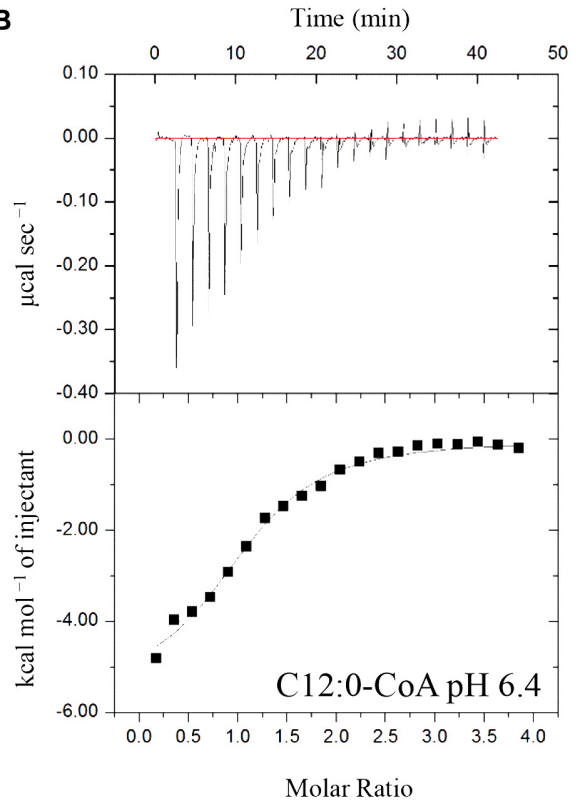

D

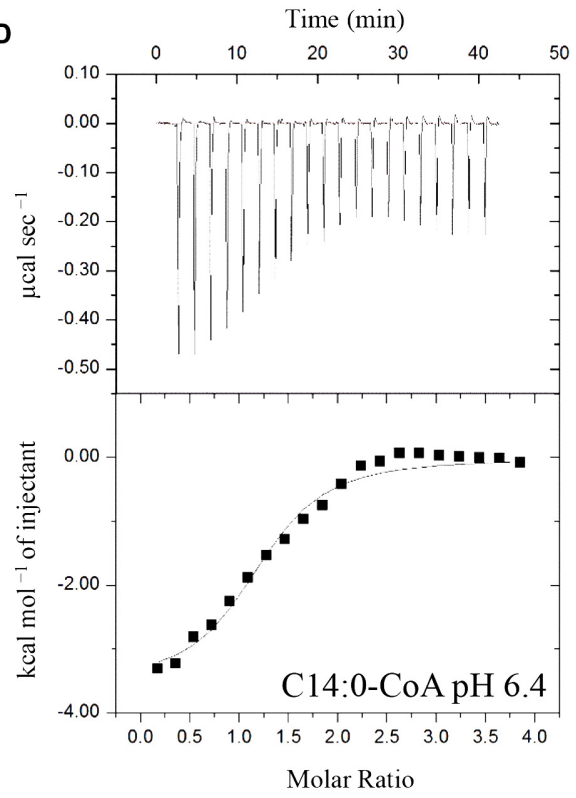

FIGURE 6 | Binding isotherms of recombinant (His)6-AtACBP3 titrated with $\mathrm{C} 12: 0$ - and $\mathrm{C} 14: 0-\mathrm{Co}$ esters at $25^{\circ} \mathrm{C}$ in isothermal titration calorimetry. The panel shows raw data of $30 \mu \mathrm{M}$ recombinant (His) $)_{6}$-AtACBP3 titrated with $600 \mu \mathrm{M}$ of C12:0-CoA ester, $\mathrm{pH}$ 7.0 (A); C12:0-CoA ester, pH 6.4 (B); C14:0-CoA ester, pH 7.0 (C) and C14:0-CoA ester, pH 6.4 (D). Each assay had three technical repeats and was repeated at least twice, each using independently prepared (His)6-AtACBP3.

A recent study also demonstrated that blockage of plastidic galactolipid biosynthesis causes overproduction of arabidopsides and leads to abnormal phloem cap lignification in Arabidopsis (Lin et al., 2016). Although little is known about the exact functions of these oxygenated galactolipids in relation to the biosynthesis of free oxylipins at a cellular level, the accumulation of MeJA in phloem exudates collected from excised leaf petioles (Figure 5) and arabidopsides in AtACBP3-OEs
(Xiao et al., 2010) strengthened the role of arabidopsides in wounding and jasmonate biosynthesis. Although it would be interesting to investigate the jasmonate content in phloem exudates collected from excised leaf petioles after wounding the leaves, transcripts of $r b c S$ and $r b c L$ can be detected in the phloem exudates collected after wounding (data not shown), indicating the phloem exudates collected after wounding contained cellular contamination from the wounded tissues, 

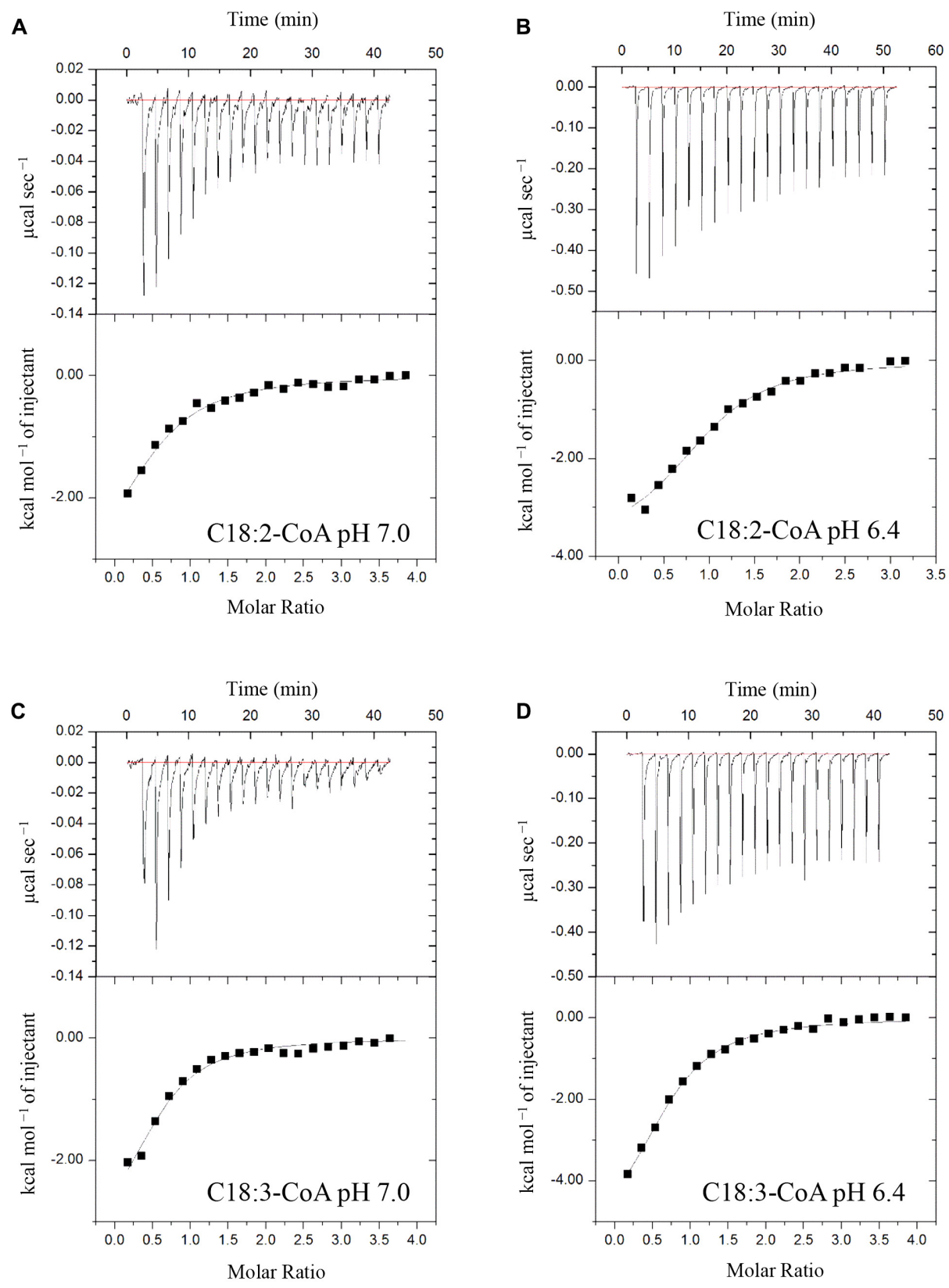

FIGURE 7 | Binding isotherms of recombinant (His) $)_{6}$-AtACBP3 titrated with $\mathrm{C} 18: 2-$ and $\mathrm{C} 18: 3-\mathrm{CoA}$ esters at $25^{\circ} \mathrm{C}$ in isothermal titration calorimetry. The panel shows raw data of $30 \mu \mathrm{M}$ recombinant (His) 6 -AtACBP3 titrated with $600 \mu \mathrm{M}$ of C18:2-CoA ester, pH 7.0 (A); C18:2-CoA ester, pH 6.4 (B); C18:3-CoA ester, pH 7.0 (C) and C18:3-CoA ester, pH 6.4 (D). Each assay had three technical repeats and was repeated at least twice, each using independently prepared (His)6-AtACBP3.

thereby preventing the analysis of jasmonate content in phloem exudates after wounding.

C12:0 - and C14:0-FA accumulation in acbp3 phloem exudates, but not in the AtACBP3-RNAi lines or the wild type (Figure 5), may have arisen from complete loss of AtACBP3 function in acbp3 but a partial loss in the AtACBP3-RNAi lines [as verified in northern blot analysis by Xiao et al. (2010)]. In canola plants, sublethal UV irradiation caused an 11-fold increase in C12:0FA and moderate accumulation of C14:0-FA in the phloem
(Madey et al., 2002). Herein, the accumulation of C12:0- and C14:0-FAs in $a c b p 3$ phloem exudates bears resemblance to similar accumulation following response to UV irradiation in canola phloem sap (Madey et al., 2002).

\section{AtACBP3 Potentially Binds}

Fatty-Acyl-CoA Esters in the Phloem

Previous in vitro Lipidex binding assays had shown that (His) 6 -AtACBP3 binds to C16:0-, C18:1- and C20:4-CoA esters 
TABLE 1 | Dissociation constants between (His)6-AtACBP3 and acyl-CoA esters.

\begin{tabular}{lccc}
\hline Acyl-CoA esters & $\mathbf{p H}$ & $\boldsymbol{K}_{\boldsymbol{D}}(\boldsymbol{\mu} \mathbf{M})$ & $\boldsymbol{n}(\mathbf{k c a l} / \mathbf{m o l})$ \\
\hline C12:0 & 7.0 & $33.1 \pm 13.0$ & $1.0 \pm 0.3$ \\
C12:0 & 6.4 & $6.1 \pm 0.9$ & $1.0 \pm 0.0$ \\
C14:0 & 7.0 & $4.0 \pm 0.6$ & $1.5 \pm 0.0$ \\
C14:0 & 6.4 & $3.3 \pm 0.8$ & $1.2 \pm 0.0$ \\
C16:1 & 7.0 & $5.1 \pm 1.9$ & $1.2 \pm 0.1$ \\
C16:1 & 6.4 & $9.7 \pm 2.1$ & $1.63 \pm 0.0$ \\
C17:0 & 7.0 & $21 \pm 4.7$ & $1.8 \pm 0.1$ \\
C17:0 & 6.4 & $3.7 \pm 1.1$ & $2 \pm 0.0$ \\
C18:2 & 7.0 & $13.4 \pm 1.4$ & $0.5 \pm 0.0$ \\
C18:2 & 6.4 & $6.4 \pm 1.0$ & $0.9 \pm 0.0$ \\
C18:3 & 7.0 & $8.6 \pm 2$ & $0.6 \pm 0.0$ \\
C18:3 & 6.4 & $9.0 \pm 0.1$ & $0.7 \pm 0.0$
\end{tabular}

Each assay had three technical repeats and was repeated at least twice using (His) 6 -AtACBP3 that was independently prepared. Standard deviations were calculated based on readings of three technical repeats.

(Leung et al., 2006). In this study, ITC demonstrated that (His) $6_{6}$ AtACBP3 not only binds medium-chain (C12:0- and C14:0-) but also long-chain (C16:1-, C17:0-, C18:2-, and C18:3-) acylCoA esters (Figures 6, 7 and Supplementary Figure S7). Some of their FA derivatives (C12:0-, C14:0-, C16:1-, and C18:2-FAs) have already been identified in Arabidopsis phloem exudate (Guelette et al., 2012). A recent study using microscale thermophoresis (MST) has shown that recombinant AtACBP3 binds long-chain (C18:2- and C20:0-) and very-long-chain (C22:0- and C24:0-) acyl-CoA esters (Xie et al., 2015). Interestingly, the $K_{D}$ values from our study and Xie et al. (2015) were both within the micromolar range.
An attempt to determine the binding affinity between (His) 6 -AtACBP3 with MeJA in ITC showed that AtACBP3 is unlikely to be a MeJA transporter in the phloem (Supplementary Figure S8). Only recently, did evidence emerge that the Arabidopsis JASMONATE TRANSPORTER1 (AtJAT1), also known as Arabidopsis ABC TRANSPORTER G FAMILY MEMBER16, is a cellular jasmonoyl-isoleucine transporter that mediates nuclear entry of jasmonoyl-isoleucine ( $\mathrm{Li}$ et al., 2017). Although jasmonate has been considered as a longdistance signal (Li et al., 2002; Thorpe et al., 2007; Sato et al., 2011), the long-distance transporter(s) of jasmonate remains elusive.

Some proteins that are involved in JA-mediated plant defence are also known to be involved in SA-mediated defence pathways. Noteworthy examples include various fatty-acid desaturases (FAD) which convert C18:2-FA to C18:3-FA, and C18:3-FA is the precursor of jasmonic acid (Zimmerman and Feng, 1978). Arabidopsis fad $3 \mathrm{fad} 7 \mathrm{fad} 8$ is deficient in C18:3-FA and is hypersensitive to insect infection (McConn et al., 1997). However, a loss-of-function mutation in tomato fad7 enhanced aphid resistance in a SA-dependent manner (Avila et al., 2012). Interestingly, AtACBP3 appears to be involved in this complex network of JA- and SA-mediated plant defence (Figure 8). AtACBP3 is induced by both JA and SA (Xiao and Chye, 2011b). Locally, the overexpression of AtACBP3 confers upregulation of PATHOGEN-RELATED genes and NONEXPRESSOR OF PR GENES1-dependent resistance to $P$. syringae (Xiao and Chye, 2011b). In this study, mechanical wounding upregulated the expression of AtACBP3 and JA marker genes in local leaves. Distally, AtACBP3 is involved in the transport of wound signalling, possibly by complexing with C18:2- and C18:3-acylCoA esters, culminating in the upregulation of JA marker genes.

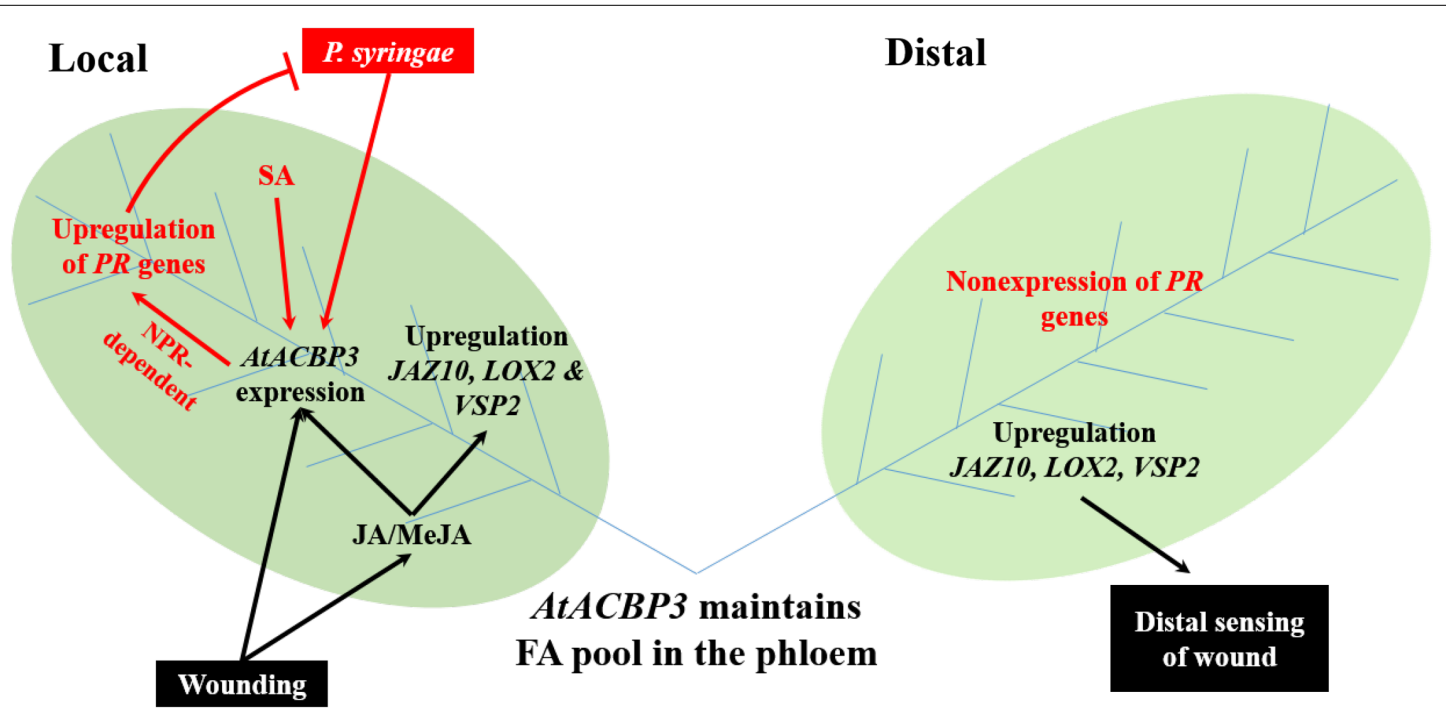

FIGURE 8 | A proposed model of AtACBP3 in plant stress responses was illustrated. Two leaves (labelled Local and Distal) are connected by vascular tissues which include phloem (blue lines) and xylem (not shown). Black colour scheme represents a JA-related pathway. Red colour scheme represents a SA-related pathway. ACC, 1-aminocyclopropane-1-carboxylic acid; AtACBP3, Arabidopsis thaliana ACYL-COA-BINDING PROTEIN3; JA, jasmonic acid; JAZ10, JASMONATE-ZIM-DOMAIN PROTEIN10; LOX2, LIPOXYGENASE2; MeJA, methyl jasmonate; NPR1, NONEXPRESSOR OF PR GENES1; PR genes, PATHOGENESIS-RELATED genes; SA, salicylic acid; VSP2, VEGETATIVE STORAGE PROTEIN2. 
However, $P R$ genes were not induced in distal tissues when Arabidopsis rosette leaves were infected distally by $P$. syringae (Xiao and Chye, 2011b). Nevertheless, our observations support AtACBP3 participation in the maintenance of a pool of FA/acylCoA esters in the phloem, similar to the role of AtACBP6 in the cytosol for jasmonate production (Ye et al., 2016a). Thus, the existence of two AtACBPs in the phloem now provides new evidence on the importance of these proteins in phloem lipid metabolism and plant defence.

\section{AUTHOR CONTRIBUTIONS}

T-HH and M-LC conceived and designed the experiments. T-HH and S-CL performed and analysed the isothermal titration calorimetry assays. T-HH performed and analysed the fatty acid analysis. M-LC, S-CL, and Z-WY provided critical advice and suggestions on the design of experiments. T-HH performed all other experiments and analysed the data. T-HH, S-CL, Z-WY and M-LC wrote the manuscript.

\section{REFERENCES}

Andersson, M. X., Hamberg, M., Kourtchenko, O., Brunnstrom, A., McPhail, K. L., Gerwick, W. H., et al. (2006). Oxylipin profiling of the hypersensitive response in Arabidopsis thaliana: formation of a novel oxo-phytodienoic acid-containing galactolipid, arabidopside E. J. Biol. Chem. 281, 31528-31537. doi: 10.1074/jbc. M604820200

Avila, C. A., Arévalo-Soliz, L. M., Jia, L., Navarre, D. A., Chen, Z., Howe, G. A., et al. (2012). Loss of function of FATTY ACID DESATURASE7 in tomato enhances basal aphid resistance in a salicylate-dependent manner. Plant Physiol. 158, 2028-2041. doi: 10.1104/pp.111.191262

Balachandran, S., Xiang, Y., Schobert, C., Thompson, G. A., and Lucas, W. J. (1997). Phloem sap proteins from Cucurbita maxima and Ricinus communis have the capacity to traffic cell to cell through plasmodesmata. Proc. Natl. Acad. Sci. U.S.A. 94, 14150-14155. doi: 10.1073/pnas.94.25.14150

Barbaglia, A. M., Tamot, B., Greve, V., and Hoffmann-Benning, S. (2016). Phloem proteomics reveals new lipid-binding proteins with a putative role in lipid-mediated signaling. Front. Plant Sci. 7:563. doi: 10.3389/fpls.2016. 00563

Bell, E., Creelman, R. A., and Mullet, J. E. (1995). A chloroplast lipoxygenase is required for wound-induced jasmonic acid accumulation in Arabidopsis. Proc. Natl. Acad. Sci. U.S.A. 92, 8675-8679. doi: 10.1073/pnas.92.19.8675

Bradford, M. M. (1976). Rapid and sensitive method for quantitation of microgram quantities of protein utilizing principle of protein-dye binding. Anal. Biochem. 72, 248-254. doi: 10.1016/0003-2697(76)90527-3

Buseman, C. M., Tamura, P., Sparks, A. A., Baughman, E. J., Maatta, S., Zhao, J., et al. (2006). Wounding stimulates the accumulation of glycerolipids containing oxophytodienoic acid and dinor-oxophytodienoic acid in Arabidopsis leaves. Plant Physiol. 142, 28-39. doi: 10.1104/pp.106.082115

Caarls, L., Pieterse, C. M. J., and Van Wees, S. C. M. (2015). How salicylic acid takes transcriptional control over jasmonic acid signaling. Front. Plant Sci. 6:170. doi: 10.3389/fpls.2015.00170

Carella, P., Isaacs, M., and Cameron, R. (2015). Plasmodesmata-located protein overexpression negatively impacts the manifestation of systemic acquired resistance and the long-distance movement of Defective in Induced Resistancel in Arabidopsis. Plant Biol. 17, 395-401. doi: 10.1111/plb.12234

Carella, P., Merl-Pham, J., Wilson, D. C., Dey, S., Hauck, S. M., Vlot, A. C., et al. (2016). Comparative proteomics analysis of phloem exudates collected during the induction of systemic acquired resistance. Plant Physiol. 171, 1495-1510. doi: 10.1104/pp.16.00269

Carvalho, A. P., and Malcata, F. X. (2005). Preparation of fatty acid methyl esters for gas-chromatographic analysis of marine lipids: Insight studies. J. Agric. Food Chem. 53, 5049-5059. doi: 10.1021/jf048788i

\section{FUNDING}

This work was supported by the Wilson and Amelia Wong Endowment Fund and the Research Grants Council of Hong Kong (HKU765813M). T-HH and Z-WY were supported by a HKU Postgraduate Scholarship and a University Postgraduate Fellowship, respectively; and S-CL by a HKU Postdoctoral Fellowship.

\section{ACKNOWLEDGMENTS}

We thank Mingfu Wang (HKU) for advice on GC-MS.

\section{SUPPLEMENTARY MATERIAL}

The Supplementary Material for this article can be found online at: https://www.frontiersin.org/articles/10.3389/fpls.2018.00002/ full\#supplementary-material

Champigny, M. J., Isaacs, M., Carella, P., Faubert, J., Fobert, P. R., and Cameron, R. K. (2013). Long distance movement of DIR1 and investigation of the role of DIR1-like during systemic acquired resistance in Arabidopsis. Front. Plant Sci. 4:230. doi: 10.3389/fpls.2013.00230

Champigny, M. J., Shearer, H., Mohammad, A., Haines, K., Neumann, M., Thilmony, R., et al. (2011). Localization of DIR1 at the tissue, cellular and subcellular levels during systemic acquired resistance in Arabidopsis using DIR1: GUS and DIR1: EGFP reporters. BMC Plant Biol. 11:125. doi: 10.1186/ 1471-2229-11-125

Chan, S. W. (2004). Identification of Mutants in Genes Encoding Arabidopsis acylCoenzyme a Binding Proteins ACBP3, ACBP4 and ACBP5. MPhil thesis, The University of Hong Kong, Pok Fu Lam. doi: 10.5353/th_b3621319.

Chauvin, A., Caldelari, D., Wolfender, J.-L., and Farmer, E. E. (2013). Four 13lipoxygenases contribute to rapid jasmonate synthesis in wounded Arabidopsis thaliana leaves: a role for lipoxygenase 6 in responses to long-distance wound signals. New Phytol. 197, 566-575. doi: 10.1111/nph.12029

Chen, Q. F., Xiao, S., and Chye, M. L. (2008). Overexpression of the Arabidopsis 10-kilodalton acyl-coenzyme A-binding protein ACBP6 enhances freezing tolerance. Plant Physiol. 148, 304-315. doi: 10.1104/pp.108.123331

Conconi, A., Miquel, M., and Ryan, C. (1996). Intracellular levels of free linolenic and linoleic acids increase in tomato leaves in response to wounding. Plant Physiol. 111, 797-803. doi: 10.1104/pp.111.3.797

Corbesier, L., Vincent, C., Jang, S., Fornara, F., Fan, Q., Searle, I., et al. (2007). FT protein movement contributes to long-distance signaling in floral induction of Arabidopsis. Science 316, 1030-1033. doi: 10.1126/science. 1141752

Creelman, R. A., and Mullet, J. E. (1997). Biosynthesis and action of jasmonates in plants. Annu. Rev. Plant Physiol. Plant Mol. Biol. 48, 355-381. doi: 10.1146/ annurev.arplant.48.1.355

De Boer, A. H., and Volkov, V. (2003). Logistics of water and salt transport through the plant: structure and functioning of the xylem. Plant Cell Environ. 26, 87-101. doi: 10.1046/j.1365-3040.2003.00930.x

Deeken, R., Ache, P., Kajahn, I., Klinkenberg, J., Bringmann, G., and Hedrich, R. (2008). Identification of Arabidopsis thaliana phloem RNAs provides a search criterion for phloem-based transcripts hidden in complex datasets of microarray experiments. Plant J. 55, 746-759. doi: 10.1111/j.1365-313X.2008. 03555.x

Du, Z. Y., Arias, T., Meng, W., and Chye, M.-L. (2016). Plant acyl-CoAbinding proteins: an emerging family involved in plant development and stress responses. Prog. Lipid Res. 63, 165-181. doi: 10.1016/j.plipres.2016. 06.002

Du, Z. Y., Chen, M. X., Chen, Q. F., Xiao, S., and Chye, M. L. (2013). Overexpression of Arabidopsis acyl-CoA-binding protein ACBP2 enhances 
drought tolerance. Plant Cell Environ. 36, 300-314. doi: 10.1111/j.1365-3040. 2012.02574.x

Du, Z. Y., Xiao, S., Chen, Q. F., and Chye, M. L. (2010). Depletion of the membraneassociated acyl-coenzyme A-binding protein ACBP1 enhances the ability of cold acclimation in Arabidopsis. Plant Physiol. 152, 1585-1597. doi: 10.1104/pp.109. 147066

Farmer, E., Mousavi, S., and Lenglet, A. (2013). Leaf numbering for experiments on long distance signalling in Arabidopsis. Protoc. Exch. doi: 10.1038/protex. 2013.071

Farmer, E. E., and Ryan, C. A. (1992). Octadecanoid precursors of jasmonic acid activate the synthesis of wound-inducible proteinase-inhibitors. Plant Cell 4, 129-134. doi: 10.1105/tpc.4.2.129

Franke, R., Briesen, I., Wojciechowski, T., Faust, A., Yephremov, A., Nawrath, C., et al. (2005). Apoplastic polyesters in Arabidopsis surface tissues - a typical suberin and a particular cutin. Phytochemistry 66, 2643-2658. doi: 10.1016/j. phytochem.2005.09.027

Gao, D. J., Knight, M. R., Trewavas, A. J., Sattelmacher, B., and Plieth, C. (2004). Self-reporting Arabidopsis expressing $\mathrm{pH}$ and $[\mathrm{Ca} 2+]$ indicators unveil ion dynamics in the cytoplasm and in the apoplast under abiotic stress. Plant Physiol. 134, 898-908. doi: 10.1104/pp.103.032508

Gasperini, D., Chauvin, A., Acosta, I. F., Kurenda, A., Stolz, S., Chételat, A., et al. (2015). Axial and radial oxylipin transport. Plant Physiol. 169, 2244-2254. doi: 10.1104/pp.15.01104

Gerbling, H., Axiotis, S., and Douce, R. (1994). A new acyl-CoA synthetase, located in higher-plant cytosol. J. Plant Physiol. 143, 561-564. doi: 10.1016/S01761617(11)81824-9

Glauser, G., Dubugnon, L., Mousavi, S. A. R., Rudaz, S., Wolfender, J. L., and Farmer, E. E. (2009). Velocity estimates for signal propagation leading to systemic jasmonic acid accumulation in wounded Arabidopsis. J. Biol. Chem. 284, 34506-34513. doi: 10.1074/jbc.M109.061432

Glauser, G., Grata, E., Dubugnon, L., Rudaz, S., Farmer, E. E., and Wolfender, J. L. (2008). Spatial and temporal dynamics of jasmonate synthesis and accumulation in Arabidopsis in response to wounding. J. Biol. Chem. 283, 16400-16407. doi: 10.1074/jbc.M801760200

Graham, J., Hall, G., Pearce, G., and Ryan, C. (1986). Regulation of synthesis of proteinase inhibitors I and II mRNAs in leaves of wounded tomato plants. Planta 169, 399-405. doi: 10.1007/BF00392137

Guelette, B. S., Benning, U. F., and Hoffmann-Benning, S. (2012). Identification of lipids and lipid-binding proteins in phloem exudates from Arabidopsis thaliana. J. Exp. Bot. 63, 3603-3616. doi: 10.1093/jxb/ers028

Hayashi, H., Fukuda, A., Suzui, N., and Fujimaki, S. (2000). Proteins in the sieve element-companion cell complexes: their detection, localization and possible functions. Aust. J. Plant Physiol. 27, 489-496. doi: 10.1071/ PP99184

Hijaz, F., and Killiny, N. (2014). Collection and chemical composition of phloem sap from Citrus sinensis L. Osbeck (sweet orange). PLOS ONE 9:e101830. doi: 10.1371/journal.pone. 0101830

His, I., Andeme-Onzighi, C., Morvan, C., and Driouich, A. (2001). Microscopic studies on mature flax fibers embedded in LR white: Immunogold localization of cell wall matrix polysaccharicles. J. Histochem. Cytochem. 49, 1525-1535. doi: $10.1177 / 002215540104901206$

Hisamatsu, Y., Goto, N., Hasegawa, K., and Shigemori, H. (2003). Arabidopsides A and B, two new oxylipins from Arabidopsis thaliana. Tetrahedron Lett. 44, 5553-5556. doi: 10.1016/S0040-4039(03)01148-1

Hisamatsu, Y., Goto, N., Sekiguchi, M., Hasegawa, K., and Shigemori, H. (2005). Oxylipins arabidopsides C and D from Arabidopsis thaliana. J. Nat. Prod. 68, 600-603. doi: 10.1021/np0495938

Hoad, G. V. (1995). Transport of hormones in the phloem of higher-plants. Plant Growth Regul. 16, 173-182. doi: 10.1007/BF00029538

Hsiao, A. S., Yeung, E. C., Ye, Z. W., and Chye, M. L. (2015). The Arabidopsis cytosolic acyl-CoA-binding proteins play combinatory roles in pollen development. Plant Cell Physiol. 56, 322-333. doi: 10.1093/pcp/pcu163

Ishiguro, S., Kawai-Oda, A., Ueda, J., Nishida, I., and Okada, K. (2001). The DEFECTIVE IN ANTHER DEHISCENCE1 gene encodes a novel phospholipase A1 catalyzing the initial step of jasmonic acid biosynthesis, which synchronizes pollen maturation, anther dehiscence, and flower opening in Arabidopsis. Plant Cell 13, 2191-2209. doi: 10.1105/tpc.13.10.2191
Ishiwatari, Y., Fujiwara, T., McFarland, K., Nemoto, K., Hayashi, H., Chino, M., et al. (1998). Rice phloem thioredoxin h has the capacity to mediate its own cell-to-cell transport through plasmodesmata. Planta 205, 12-22. doi: 10.1007/ s004250050291

Jefferson, R. A., Kavanagh, T. A., and Bevan, M. W. (1987). Gus fusions - betaglucuronidase as a sensitive and versatile gene fusion marker in higher-plants. EMBO J. 6, 3901-3907.

Koo, A. J., and Howe, G. A. (2009). The wound hormone jasmonate. Phytochemistry 70, 1571-1580. doi: 10.1016/j.phytochem.2009.07.018

Kourtchenko, O., Andersson, M. X., Hamberg, M., Brunnstrom, A., Gobel, C., McPhail, K. L., et al. (2007). Oxo-phytodienoic acid-containing galactolipids in Arabidopsis: jasmonate signaling dependence. Plant Physiol. 145, 1658-1669. doi: $10.1104 / \mathrm{pp} \cdot 107.104752$

Lascombe, M. B., Bakan, B., Buhot, N., Marion, D., Blein, J. P., Larue, V., et al. (2008). The structure of "defective in induced resistance" protein of Arabidopsis thaliana, DIR1, reveals a new type of lipid transfer protein. Protein Sci. 17, 1522-1530. doi: 10.1110/ps.035972.108

Lee, J. Y., Wang, X., Cui, W., Sager, R., Modla, S., Czymmek, K., et al. (2011). A plasmodesmata-localized protein mediates crosstalk between cell-to-cell communication and innate immunity in Arabidopsis. Plant Cell 23, 3353-3373. doi: $10.1105 /$ tpc. 111.087742

Leung, K. C., Li, H. Y., Xiao, S., Tse, M. H., and Chye, M. L. (2006). Arabidopsis ACBP3 is an extracellularly targeted acyl-CoA-binding protein. Planta 223 , 871-881. doi: 10.1007/s00425-005-0139-2

Li, L., Li, C., Lee, G. I., and Howe, G. A. (2002). Distinct roles for jasmonate synthesis and action in the systemic wound response of tomato. Proc. Natl. Acad. Sci. U.S.A. 99, 6416-6421. doi: 10.1073/pnas.072072599

Li, Q., Zheng, J., Li, S., Huang, G., Skilling, S. J., Wang, L., et al. (2017). Transportermediated nuclear entry of jasmonoyl-isoleucine is essential for jasmonate signaling. Mol. Plant 10, 695-708. doi: 10.1016/j.molp.2017.01.010

Liao, P., Chen, Q. F., and Chye, M. L. (2014). Transgenic Arabidopsis flowers overexpressing acyl-CoA-binding protein ACBP6 are freezing tolerant. Plant Cell Physiol. 55, 1055-1071. doi: 10.1093/pcp/pcu037

Lin, Y. T., Chen, L. J., Herrfurth, C., Feussner, I., and Li, H. M. (2016). Reduced biosynthesis of digalactosyldiacylglycerol, a major chloroplast membrane lipid, leads to oxylipin overproduction and phloem cap lignification in Arabidopsis. Plant Cell 28, 219-232. doi: 10.1105/tpc.15.01002

Liu, Y. L., Ahn, J. E., Datta, S., Salzman, R. A., Moon, J., HuyghuesDespointes, B., et al. (2005). Arabidopsis vegetative storage protein is an antiinsect acid phosphatase. Plant Physiol. 139, 1545-1556. doi: 10.1104/pp.105. 066837

Lung, S. C., Liao, P., Yeung, E. C., Hsiao, A. S., Xue, Y., and Chye, M. L. (2017). Acyl-CoA-binding protein ACBP1 modulates sterol synthesis during embryogenesis. Plant Physiol. 174, 1420-1435. doi: 10.1104/pp.17.00412

Madey, E., Nowack, L. M., and Thompson, J. E. (2002). Isolation and characterization of lipid in phloem sap of canola. Planta 214, 625-634. doi: $10.1007 /$ s004250100649

Maldonado, A. M., Doerner, P., Dixon, R. A., Lamb, C. J., and Cameron, R. K. (2002). A putative lipid transfer protein involved in systemic resistance signalling in Arabidopsis. Nature 419, 399-403. doi: 10.1038/nature00962

Mathieu, J., Warthmann, N., Kuttner, F., and Schmid, M. (2007). Export of FT protein from phloem companion cells is sufficient for floral induction in Arabidopsis. Curr. Biol. 17, 1055-1060. doi: 10.1016/j.cub.2007.05.009

McConn, M., Creelman, R. A., Bell, E., and Mullet, J. E. (1997). Jasmonate is essential for insect defense in Arabidopsis. Proc. Natl. Acad. Sci. U.S.A. 94, 5473-5477. doi: 10.1073/pnas.94.10.5473

Mitton, F. M., Pinedo, M. L., and de la Canal, L. (2009). Phloem sap of tomato plants contains a DIR1 putative ortholog. J. Plant Physiol. 166, 543-547. doi: 10.1016/j.jplph.2008.07.002

Mousavi, S. A. R., Chauvin, A., Pascaud, F., Kellenberger, S., and Farmer, E. E. (2013). GLUTAMATE RECEPTOR-LIKE genes mediate leaf-to-leaf wound signalling. Nature 500, 422-429. doi: 10.1038/nature12478

Nalam, V. J., Keeretaweep, J., Sarowar, S., and Shah, J. (2012). Root-derived oxylipins promote green peach aphid performance on Arabidopsis foliage. Plant Cell 24, 1643-1653. doi: 10.1105/tpc.111.094110

Narváez-Vásquez, J., Florin-Christensen, J., and Ryan, C. A. (1999). Positional specificity of a phospholipase A activity induced by wounding, systemin, 
and oligosaccharide elicitors in tomato leaves. Plant Cell 11, 2249-2260. doi: 10.1105/tpc.11.11.2249

Ohlrogge, J., and Browse, J. (1995). Lipid biosynthesis. Plant Cell 7, 957-970. doi: 10.1105/tpc.7.7.957

Riesmeier, J. W., Willmitzer, L., and Frommer, W. B. (1994). Evidence for an essential role of the sucrose transporter in phloem loading and assimilate partitioning. ЕMBO J. 13, 1-7.

Sanders, P. M., Lee, P. Y., Biesgen, C., Boone, J. D., Beals, T. P., Weiler, E. W., et al. (2000). The Arabidopsis DELAYED DEHISCENCE1 gene encodes an enzyme in the jasmonic acid synthesis pathway. Plant Cell 12, 1041-1061. doi: 10.1105/tpc.12.7.1041

Sato, C., Aikawa, K., Sugiyama, S., Nabeta, K., Masuta, C., and Matsuura, H. (2011). Distal transport of exogenously applied jasmonoyl-isoleucine with wounding stress. Plant Cell Physiol. 52, 509-517. doi: 10.1093/pcp/pcr011

Schulz, A. (1998). Phloem, structure related to function. Progr. Bot. 59, 429-475. doi: 10.1007/978-3-642-80446-5_16

Shah, J. (2009). Plants under attack: systemic signals in defence. Curr. Opin. Plant Biol. 12, 459-464. doi: 10.1016/j.pbi.2009.05.011

Srivastava, A. C., Ganesan, S., Ismail, I. O., and Ayre, B. G. (2008). Functional characterization of the Arabidopsis AtSUC2 sucrose/H+ symporter by tissuespecific complementation reveals an essential role in phloem loading but not in long-distance transport. Plant Physiol. 148, 200-211. doi: 10.1104/pp.108. 124776

Stelmach, B. A., Muller, A., Hennig, P., Gebhardt, S., Schubert-Zsilavecz, M., and Weiler, E. W. (2001). A novel class of oxylipins, sn1-O-(12-oxophytodienoyl)sn2-O-(hexadecatrienoyl)-monogalactosyl diglyceride, from Arabidopsis thaliana. J. Biol. Chem. 276, 12832-12838. doi: 10.1074/jbc.M010743200

Suzui, N., Nakamura, S., Fujiwara, T., Hayashi, H., and Yoneyama, T. (2006). A putative acyl-CoA-binding protein is a major phloem sap protein in rice (Oryza sativa L.). J. Exp. Bot. 57, 2571-2576. doi: 10.1093/jxb/erl021

Thorpe, M. R., Ferrieri, A. P., Herth, M. M., and Ferrieri, R. A. (2007). 11Cimaging: methyl jasmonate moves in both phloem and xylem, promotes transport of jasmonate, and of photoassimilate even after proton transport is decoupled. Planta 226, 541-551. doi: 10.1007/s00425-007-0503-5

Turnbull, C. G. N., Booker, J. P., and Leyser, H. M. O. (2002). Micrografting techniques for testing long-distance signalling in Arabidopsis. Plant J. 32, 255-262. doi: 10.1046/j.1365-313X.2002.01419.x

Vijayan, P., Shockey, J., Lévesque, C. A., and Cook, R. J. (1998). A role for jasmonate in pathogen defense of Arabidopsis. Proc. Natl. Acad. Sci. U.S.A. 95, 7209-7214. doi: 10.1073/pnas.95.12.7209

Wang, L., Kazachkov, M., Shen, W., Bai, M., Wu, H., and Zou, J. (2014). Deciphering the roles of Arabidopsis LPCAT and PAH in phosphatidylcholine homeostasis and pathway coordination for chloroplast lipid synthesis. Plant J. 80, 965-976. doi: 10.1111/tpj.12683

Warwick, N., Somerville, C., and Slack, C. (1986). Fluxes through the prokaryotic and eukaryotic pathways of lipid synthesis in the '16:3'plant Arabidopsis thaliana. Biochem. J. 235, 25-31. doi: 10.1042/bj2350025

Xia, Y., Yu, K., Gao, Q. M., Wilson, E. V., Navarre, D., Kachroo, P., et al. (2012). Acyl CoA binding proteins are required for cuticle formation and plant responses to microbes. Front. Plant Sci. 3:224. doi: 10.3389/fpls.2012.00224

Xiao, S., and Chye, M. L. (2009). An Arabidopsis family of six acyl-CoA-binding proteins has three cytosolic members. Plant Physiol. Biochem. 47, 479-484. doi: 10.1016/j.plaphy.2008.12.002

Xiao, S., and Chye, M. L. (2011a). New roles for acyl-CoA-binding proteins (ACBPs) in plant development, stress responses and lipid metabolism. Prog. Lipid Res. 50, 141-151. doi: 10.1016/j.plipres.2010.11.002

Xiao, S., and Chye, M. L. (2011b). Overexpression of Arabidopsis ACBP3 enhances NPR1-dependent plant resistance to Pseudomonas syringe pv tomato DC3000. Plant Physiol. 156, 2069-2081. doi: 10.1104/pp.111.176933

Xiao, S., Gao, W., Chen, Q. F., Chan, S. W., Zheng, S. X., Ma, J. Y., et al. (2010). Overexpression of Arabidopsis acyl-CoA binding protein ACBP3 promotes starvation-induced and age-dependent leaf senescence. Plant Cell 22, 1463-1482. doi: 10.1105/tpc.110.075333

Xiao, S., Gao, W., Chen, Q. F., Ramalingam, S., and Chye, M. L. (2008). Overexpression of membrane-associated acyl-CoA-binding protein ACBP1 enhances lead tolerance in Arabidopsis. Plant J. 54, 141-151. doi: 10.1111/j. 1365-313X.2008.03402.x

Xie, L. J., Yu, L. J., Chen, Q. F., Wang, F. Z., Huang, L., Xia, F. N., et al. (2015). Arabidopsis acyl-CoA-binding protein ACBP3 participates in plant response to hypoxia by modulating very-long-chain fatty acid metabolism. Plant J. 81, 53-67. doi: 10.1111/tpj.12692

Xoconostle-Cazares, B., Yu, X., Ruiz-Medrano, R., Wang, H. L., Monzer, J., Yoo, B. C., et al. (1999). Plant paralog to viral movement protein that potentiates transport of mRNA into the phloem. Science 283, 94-98. doi: 10.1126/science. 283.5398 .94

Xue, Y., Xiao, S., Kim, J., Lung, S. C., Chen, L., Tanner, J. A., et al. (2014). Arabidopsis membrane-associated acyl-CoA-binding protein ACBP1 is involved in stem cuticle formation. J. Exp. Bot. 65, 5473-5483. doi: 10.1093/jxb/ eru304

Yan, Y. X., Stolz, S., Chetelat, A., Reymond, P., Pagni, M., Dubugnon, L., et al. (2007). A downstream mediator in the growth repression limb of the jasmonate pathway. Plant Cell 19, 2470-2483. doi: 10.1105/tpc.107.050708

Ye, Z. W., Chen, Q. F., and Chye, M. L. (2017). Arabidopsis thaliana Acyl-CoA-binding protein ACBP6 interacts with plasmodesmata-located protein PDLP8. Plant Signal. Behav. 12:e1359365. doi: 10.1080/15592324.2017. 1359365

Ye, Z. W., and Chye, M. L. (2016). Plant cytosolic acyl-CoA-binding proteins. Lipids 51, 1-13. doi: 10.1007/s11745-015-4103-Z

Ye, Z. W., Lung, S. C., Hu, T. H., Chen, Q. F., Suen, Y. L., Wang, M., et al. (2016a). Arabidopsis acyl-CoA-binding protein ACBP6 localizes in the phloem and affects jasmonate composition. Plant Mol. Biol. 92, 717-730.

Ye, Z. W., Xu, J., Shi, J., Zhang, D., and Chye, M. L. (2016b). Kelch-motif containing acyl-CoA binding proteins AtACBP4 and AtACBP5 are differentially expressed and function in floral lipid metabolism. Plant Mol. Biol. 93, 209-225. doi: 10.1007/s11103-016-0557-5

Yoo, B. C., Lee, J. Y., and Lucas, W. J. (2002). Analysis of the complexity of protein kinases within the phloem sieve tube system-characterization of Cucurbita maxima calmodulin-like domain protein kinase 1. J. Biol. Chem. 277, 15325-15332. doi: 10.1074/jbc.M200382200

Yurchenko, O. P., Nykiforuk, C. L., Moloney, M. M., Stahl, U., Banas, A., Stymne, S., et al. (2009). A $10-\mathrm{kDa}$ acyl-CoA-binding protein (ACBP) from Brassica napus enhances acyl exchange between acyl-CoA and phosphatidylcholine. Plant Biotechnol. J. 7, 602-610. doi: 10.1111/j.1467-7652. 2009.00427.x

Zheng, S. X., Xiao, S., and Chye, M. L. (2012). The gene encoding Arabidopsis acyl-CoA-binding protein 3 is pathogen inducible and subject to circadian regulation. J. Exp. Bot. 63, 2985-3000. doi: 10.1093/jxb/ ers009

Zimmerman, D., and Feng, P. (1978). Characterization of a prostaglandin-like metabolite of linolenic acid produced by a flaxseed extract. Lipids 13, 313-316. doi: $10.1007 / \mathrm{BF} 02533720$

Conflict of Interest Statement: The authors declare that the research was conducted in the absence of any commercial or financial relationships that could be construed as a potential conflict of interest.

Copyright (c) $2018 \mathrm{Hu}$, Lung, Ye and Chye. This is an open-access article distributed under the terms of the Creative Commons Attribution License (CC BY). The use, distribution or reproduction in other forums is permitted, provided the original author(s) and the copyright owner are credited and that the original publication in this journal is cited, in accordance with accepted academic practice. No use, distribution or reproduction is permitted which does not comply with these terms. 